\title{
Holo-APP and G-protein-mediated signaling are required for SAPP $\alpha$-induced activation of the Akt survival pathway
}

\author{
N Milosch ${ }^{1}$, G Tanriöver ${ }^{1}$, A Kundu ${ }^{1}$, A Rami ${ }^{2}$, J-C François ${ }^{3}$, F Baumkötter ${ }^{4}$, SW Weyer ${ }^{5}$, A Samanta ${ }^{6}$, A Jäschke ${ }^{6}$, F Brod $^{7}$, \\ CJ Buchholz ${ }^{7}$, S Kins ${ }^{4}$, C Behl ${ }^{8}$, UC Müller ${ }^{5}$ and D Kögel ${ }^{*, 1}$
}

Accumulating evidence indicates that loss of physiologic amyloid precursor protein (APP) function leads to reduced neuronal plasticity, diminished synaptic signaling and enhanced susceptibility of neurons to cellular stress during brain aging. Here we investigated the neuroprotective function of the soluble APP ectodomain SAPP $\alpha$ (soluble APP $\alpha$ ), which is generated by cleavage of APP by $\alpha$-secretase along the non-amyloidogenic pathway. Recombinant SAPP $\alpha$ protected primary hippocampal neurons and SH-SY5Y neuroblastoma cells from cell death induced by trophic factor deprivation. We show that this protective effect is abrogated in neurons from APP-knockout animals and APP-depleted SH-SY5Y cells, but not in APP-like protein 1- and 2- (APLP1 and APLP2) depleted cells, indicating that expression of membrane-bound holo-APP is required for sAPP $\alpha$-dependent neuroprotection. Trophic factor deprivation diminished the activity of the Akt survival pathway. Strikingly, both recombinant SAPP $\alpha$ and the APP-E1 domain were able to stimulate Akt activity in wild-type (wt) fibroblasts, SH-SY5Y cells and neurons, but failed to rescue in APP-deficient neurons or fibroblasts. The ADAM10 (a disintegrin and metalloproteinase domain-containing protein 10) inhibitor Gl254023X exacerbated neuron death in organotypic (hippocampal) slice cultures of wt mice subjected to trophic factor and glucose deprivation. This cell death-enhancing effect of Gl254023X could be completely rescued by applying exogenous SAPP $\alpha$. Interestingly, SAPP $\alpha$-dependent Akt induction was unaffected in neurons of APP- $\triangle \mathrm{CT} 15$ mice that lack the C-terminal YENPTY motif of the APP intracellular region. In contrast, sAPP $\alpha$-dependent rescue of Akt activation was completely abolished in APP mutant cells lacking the G-protein interaction motif located in the APP C-terminus and by blocking G-proteindependent signaling with pertussis toxin. Collectively, our data provide new mechanistic insights into the physiologic role of APP in antagonizing neurotoxic stress: they suggest that cell surface APP mediates SAPP $\alpha$-induced neuroprotection via G-protein-coupled activation of the Akt pathway.

Cell Death and Disease (2014) 5, e1391; doi:10.1038/cddis.2014.352; published online 28 August 2014

Despite a vast number of studies supporting the pathophysiologic relevance of the amyloid precursor protein (APP) and its metabolism, its physiologic roles are still poorly understood. ${ }^{1-3}$ There are two major pathways of APP processing. In the amyloidogenic pathway, APP is cleaved by $\beta$-secretase at the $\mathrm{N}$-terminus of the amyloid $\beta(\mathrm{A} \beta)$ domain liberating $\mathrm{SAPP} \beta$ and membrane-bound C-terminal stubs (CTF $\beta$ ) that can be further processed by the activity of $\gamma$-secretase to yield $\mathrm{A} \beta$, the major constituent of senile plaques. ${ }^{4}$ However, under physiologic conditions the majority of APP is processed by $\alpha$-secretase, ADAM10 (a disintegrin and metalloproteinase domain-containing protein 10), via the non-amyloidogenic pathway, and thus leading to secretion of SAPP $\alpha$ and preventing the generation of $A \beta .^{4,5}$ APP is a multifunctional protein implicated in several physiologic processes, including neuronal excitability, synaptic plasticity, neurite outgrowth, synaptogenesis and cell survival. ${ }^{1,6}$ Therefore, loss of these physiologic APP functions might be implicated in reduced neuronal plasticity, diminished synaptic signaling and enhanced susceptibility of neurons to cellular stress during brain aging, which ultimately may lead to neurodegeneration. In line with this notion, decreased levels of soluble APPs were detected in the cerebrospinal fluid of patients with Alzheimer's disease (AD). ${ }^{7}$ It is also established that non-cleaved APP

\footnotetext{
${ }^{1}$ Experimental Neurosurgery, Goethe University Hospital, Frankfurt am Main, Germany; ${ }^{2}$ Institute of Cellular and Molecular Anatomy (Anatomie III), Frankfurt University Hospital, Frankfurt am Main, Germany; ${ }^{3}$ Inserm and Sorbonne Universities, UPMC, Research Center Saint-Antoine, Paris, France; ${ }^{4}$ Division of Human Biology and Human Genetics, Technical University of Kaiserslautern, Kaiserslautern, Germany; ${ }^{5}$ Department of Bioinformatics and Functional Genomics, Institute of Pharmacy and Molecular Biotechnology, Heidelberg University, Heidelberg, Germany; ${ }^{6}$ Department of Pharmaceutical Chemistry, Institute of Pharmacy and Molecular Biotechnology, Heidelberg University, Heidelberg, Germany; ${ }^{7}$ Molecular Biotechnology and Gene Therapy, Paul-Ehrlich-Institut, Langen, Germany and ${ }^{8}$ Institute for Pathobiochemistry, University Medical Center, Mainz University, Mainz, Germany

*Corresponding author: D Kögel, Experimental Neurosurgery, Goethe University Hospital, Theodor-Stern-Kai 7, D-60590, Frankfurt am Main, Germany. Tel: +49 696301 6940; Fax: +49696301 5575; E-mail: koegel@em.uni-frankfurt.de

Abbreviations: $A \beta$, amyloid beta; AD, Alzheimer's disease; ADAM10, a disintegrin and metalloproteinase domain-containing protein 10; AICD, APP intracellular domain; APP, amyloid precursor protein; APLP1, APP-like protein 1; APLP2, APP-like protein 2; CA1, cornu ammonis (region) 1; GAPDH, glyceraldehyde 3-phosphate dehydrogenase; GSK3 $\alpha / \beta$, glycogen synthase kinase $3 \alpha / \beta$; IGF1, insulin-like growth factor 1; IGF1-R, insulin-like growth factor 1 receptor; IR, insulin receptor; JNK, c-Jun N-terminal kinase; MEF, mouse embryonic fibroblast; PI, propidium iodide; PI3K, phosphatidylinositide 3-kinase; PTX, Pertussis toxin; PTBD, phosphotyrosinebinding domain; SAPP $\alpha / \beta$, soluble APP $\alpha / \beta ;$ TM, transmembrane domain

Received 07.2.14; revised 10.6.14; accepted 21.7.14; Edited by G Schiavo
} 
(and the mammalian paralogs APP-like protein 1 and 2 (APLP1/APLP2)) are integral transmembrane proteins with proposed functions as membrane-bound signaling receptors and/or adhesion molecules. ${ }^{8-10}$ Despite the experimental evidence supporting the different functions of APP, it is currently unclear whether these functions are primarily mediated by transmembrane APP or by its soluble ectodomain shed from the cell surface. Based on existing evidence, it is also conceivable that membrane-anchored APP and secreted APP fragments share equal relevance in mediating the diverse physiologic roles of APP.

In vivo APP appears to be involved in damage responses and was found to be upregulated during brain injury in mammals and lower organisms. ${ }^{11-15}$ In line with this hypothesis, SAPP $\alpha$ was shown to exert protective effects following traumatic, ischemic and excitotoxic brain injury. ${ }^{16-20}$ There is also strong evidence supporting a neuroprotective function of APP and SAPP $\alpha$ in vitro, ${ }^{21-31}$ but the cellular receptor and the intracellular downstream targets mediating these neuroprotective effects remain to be identified. ${ }^{32}$ Earlier work pointed to a role of SAPP $\alpha$ in the modulation of ion homeostasis and it was proposed that $\operatorname{sAPP} \alpha$-mediated neuroprotection may be associated both with rapid effects on ion channel function and with delayed transcriptiondependent processes. ${ }^{33}$ SAPP $\alpha$ was proposed to activate potassium channels and suppress NMDA currents to limit $\mathrm{Ca}^{2+}$ overloading and excitotoxic damage in neurons. ${ }^{21,34,35}$ However, these studies also revealed that prolonged incubation with SAPP $\alpha$ over several hours was required to achieve significant effects on neuronal cell viability. Therefore, the neuroprotective function of APP/SAPP $\alpha$ is likely to be mediated by the prolonged activation of cell survival signaling pathways. $^{32}$

We have previously demonstrated that $\mathrm{APP} / \mathrm{SAPP} \alpha$ can antagonize the activation of the c-Jun N-terminal kinase (JNK) pathway that represents a central stress signaling pathway and critical upstream modulator of the mitochondrial pathway of apoptosis. ${ }^{36}$ Furthermore, we and others have shown that the phosphatidylinositide 3-kinase (PI3K)/Akt pathway is involved in mediating the protective function of APP. ${ }^{37-39}$ Of note, upstream JNK kinases such as mixed lineage kinase 3 and apoptosis signal-regulating kinase-1 (ASK1) can be inhibited via phosphorylation by Akt, suggesting crosstalk between stress and survival pathways modulated by APP. ${ }^{32}$ In addition to suppression of stress signaling, activation of survival pathways by $\operatorname{sAPP} \alpha$ may also lead to the induction of prosurvival genes involved in stress responses and neuronal survival (manganese superoxide dismutase, peroxiredoxins, catalase). ${ }^{25,29}$ Despite these observations, the cellular receptor mediating the neuroprotective functions of SAPP $\alpha$ and the exact molecular mechanisms underlying SAPP $\alpha$-dependent neuroprotective signaling have hitherto remained elusive.

Here we applied purified recombinant SAPP $\alpha$ in combination with a large set of knockdown (KD) and knockout (KO) models as well as APP mutants to further investigate the molecular mechanisms of SAPP $\alpha$-induced neuroprotection. We found that transmembranous APP acts as an $\operatorname{sAPP} \alpha$ receptor-mediating activation of the Akt survival pathway in a G-protein-dependent manner.

\section{Results}

Recombinant SAPP $\alpha$ and E1 promote cell survival only in the presence of holo-APP. As outlined above, it has been shown that $\operatorname{SAPP} \alpha$ has neuroprotective properties under various stress conditions. To investigate the potential contribution of endogenous APP for SAPP $\alpha$-induced neuroprotection, we performed a stable lentiviral KD of APP in human SH-SY5Y cells (Figure 1a). Cell viability/death was analyzed by quantification of ATP levels (Figures $1 \mathrm{~b}$ and $\mathrm{c}$ ) and microscopical evaluation of propidium iodide (PI) uptake (Figures 1d and e). Human insulin-like growth factor 1 (IGF1) served as a positive control for activation of cell survival. Recombinant, yeast-derived $\operatorname{SAPP} \alpha$ and its subdomain $\mathrm{E} 1$ exerted dose-dependent antiapoptotic effects in wild-type (wt) human SH-SY5Y subjected to trophic factor withdrawal (Figures $1 b$ and $d$ ). Both $\operatorname{SAPP} \alpha$ and its subdomain E1 failed to antagonize stress-triggered cell death in cells lacking endogenous APP, suggesting that the expression of holo-APP may be necessary for the neuroprotective functions of exogenously applied $\operatorname{sAPP} \alpha$ (Figures 1c and e). The requirement of endogenous APP for the protective effects of $S A P P \alpha$ was also confirmed in mouse embryonic fibroblasts (MEFs) derived from APP-KO versus littermate control mice that were subjected to trophic factor/ glucose withdrawal using a calcein/ethidium homodimer-3based assay (Figure 2a) and FACS analysis of PI uptake (Figure 2b).

The neuroprotective function of $\operatorname{SAPP} \alpha$ was further substantiated in tissue models when analyzing organotypic (hippocampal) slice cultures prepared from wt or APP-KO mice (Figure 3 ). There was a pronounced increase of $\mathrm{PI}-$ positive cells in serum/glucose-deprived hippocampal slice cultures, which was significantly reduced in the presence of recombinant SAPP $\alpha$. Importantly, this effect was visible only in wt slices (Figure 3b, upper panel) and not in slices from APP-KO animals (Figure $3 b$, lower panel). When applying the specific ADAM10 ( $\alpha$-secretase) inhibitor GI254023X $(5 \mu \mathrm{M})^{40}$ to serum/glucose-deprived slices, $\mathrm{PI}$ counts were significantly increased in comparison with DSMO (carrier)-treated controls. This observation suggests that the absence of endogenous SAPP $\alpha$ exacerbates cell death under these conditions. This cell death-enhancing effect of GI254023X could be completely rescued by applying exogenous SAPP $\alpha$, thereby supporting the notion that recombinant $\operatorname{SAPP} \alpha$ can substitute endogenous $\operatorname{SAPP} \alpha$ function (Figure $3 c$ ). Microscopic quantification of Pl-stained cells in the cornu ammonis (region) 1 (CA1) region of the hippocampus confirmed SAPP $\alpha$-dependent neuroprotection in wt versus APP-KO cultures and increased cell death in GI254023Xtreated slices that was compensated by recombinant $\operatorname{SAPP} \alpha$ (Figure 3d).

Recombinant SAPP $\alpha$ and APP-E1 domain activate the PI3K/Akt survival pathway, which requires the expression of holo-APP but not APLP1 or APLP2. Next, we performed in vitro Akt kinase assays with serum-deprived SH-SY5Y neuroblastoma cells to investigate directly the activation of the PI3K/Akt survival pathway by SAPP $\alpha{ }^{37,38}$ As seen in Figure 4, trophic factor withdrawal lead to a 
a

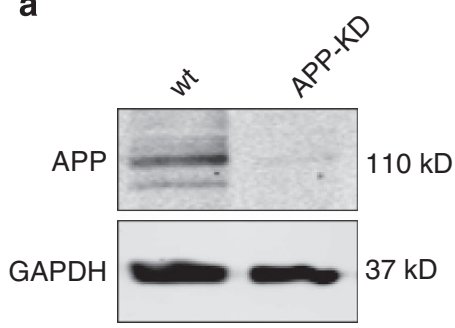

b

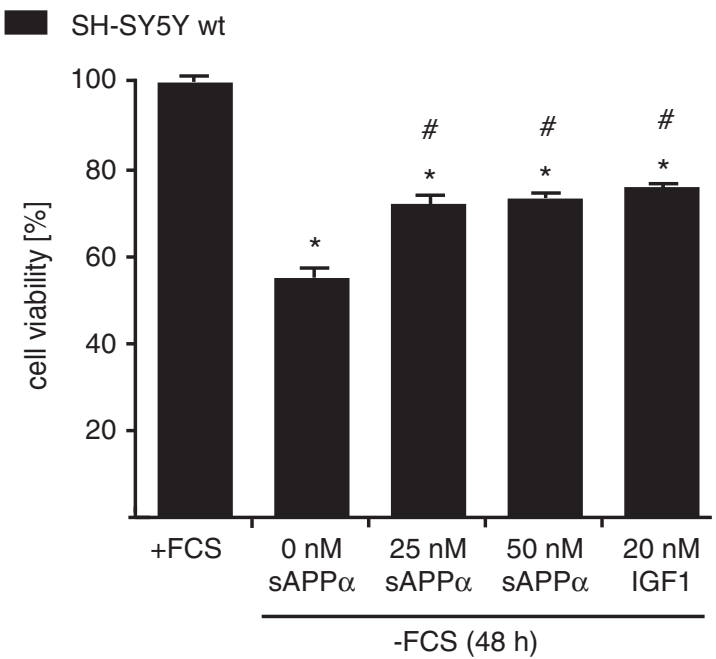

d

SH-SY5Y wt

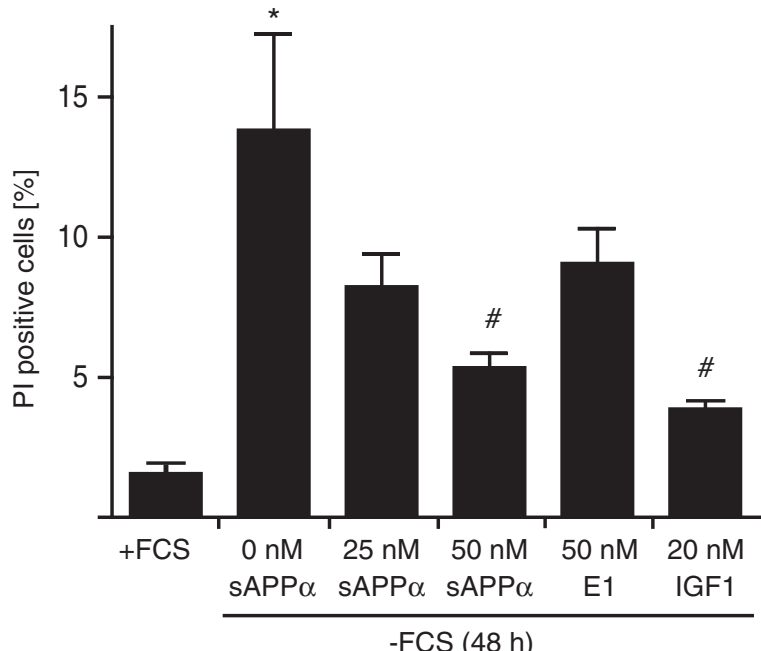

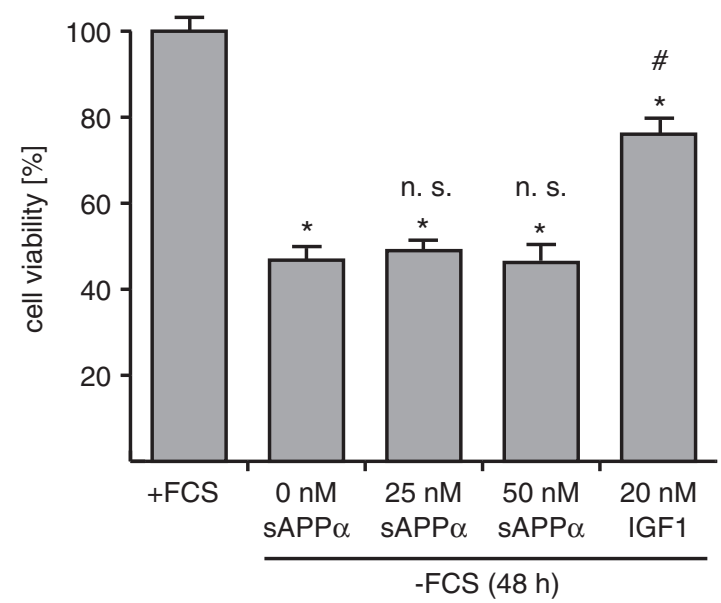

e

SH-SY5Y APP-KD

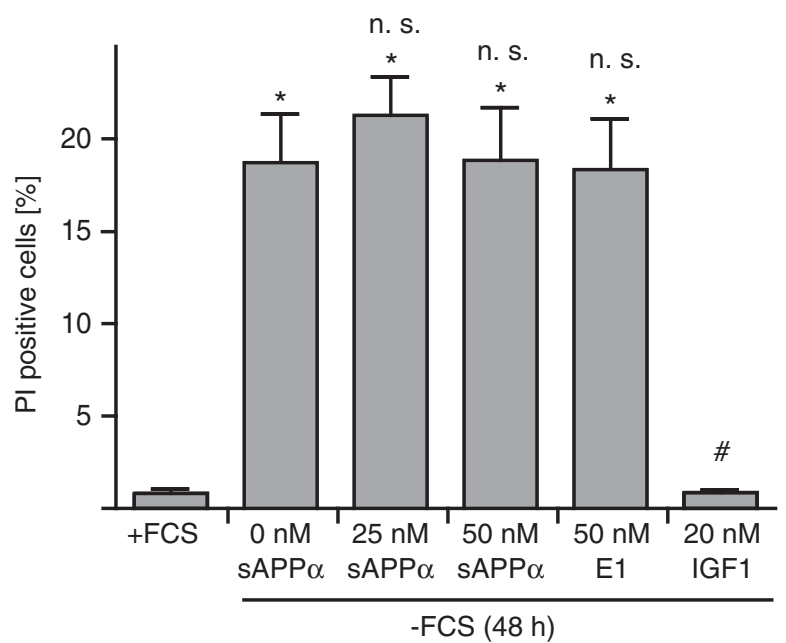

Figure 1 Recombinant SAPP $\alpha$ and E1 promote cell survival only in the presence of endogenous holo-APP. Human wt or KD SH-SY5Y neuroblastoma cells (a) were cultured in full medium $(+F C S)$ or in medium lacking trophic factors ( $-F C S)$ for $48 \mathrm{~h}$ to induce cell death $(\mathbf{b}$ and $\mathbf{c})$. In parallel, cells were treated with increasing doses of recombinant 6-His-SAPP $\alpha$ purified from yeast or IGF1 as positive control activating cell survival. Cell viability was measured photometrically in a bioluminescence assay by quantifying ATP levels. Serum deprived SH-SY5Y wt (d) or APP-KD (e) cells were treated with increasing doses of 6-His-SAPP $\alpha$ or recombinant E1. Cell death was assessed microscopically by counting PI-stained (dead) cells in three random visual fields ( $>150$ cells) and calculated as a percentage of the total number of visualized cells (Hoechst staining). Data are means from four to ten cultures \pm S.E.M. Statistical significance: ${ }^{*} P<0.05$ compared with controls ( + FCS); ${ }^{*} P<0.05$ compared with serum withdrawal in the absence of SAPP $\alpha / E 1 / / G F 1 ; N S=$ not significant

pronounced decrease of Akt activity and pGSK3 $\beta$ (glycogen synthase kinase $3 \beta$ ) levels, which was prevented by increasing doses of yeast-derived $\operatorname{SAPP} \alpha$ and the APP-E1 domain alone. Again, this was only observed in
APP-expressing wt cells (Figure 4a, left panel), while SH-SY5Y APP-KD cells did not show any SAPP $\alpha$-mediated Akt activation (Figure 4a, right panel). To rule out possible protective activities caused by components of the yeast 
medium still present in purified $\mathrm{SAPP} \alpha$ and $\mathrm{E} 1$, we also tested heat-inactivated fractions, which did not show any rescuing effects (Supplementary Figure 1A). Quantification of the blots $(n=3)$ confirmed significant induction of Akt activity (Figure 4b, left panel) and enhanced pGSK3 $\beta$ levels (Figure $4 \mathrm{~b}$, right panel) for $\mathrm{SAPP} \alpha$ and recombinant $\mathrm{E} 1$ in wt cells. In APP-KD cells, only treatment with IGF1 induced phosphorylation of GSK3 $\beta$ to a significant degree. Retransfection of APP-KD cells with a holo-APP wt construct restored the SAPP $\alpha$-dependent Akt activation (Figure 4c). To further substantiate our findings, we subsequently used hippocampal neurons derived from APP-KO and wt mice. As seen in APP-depleted neuroblastoma cells before, APP-KO neurons failed to show SAPP $\alpha$-dependent Akt activation that could, however, be readily detected in wt neurons (Figure 4d). Again, these results could be verified by quantification of western blot data (Figure 4e).

To test the possible redundancy of endogenous APP with the APP family members APLP1 and APLP2, we also performed experiments with stable SH-SY5Y APLP1 and APLP2 KD cells (Figure 5a). Interestingly, both Akt pathway activity (Figures $5 \mathrm{~b}$ and $\mathrm{c}$ ) and cell survival, as measured by $\mathrm{PI}$ staining (Figures $5 d$ and e), were mediated by SAPP $\alpha$ and the E1 domain independent of APLP1 or APLP2 expression.

The APP C-terminal domain but not the YENPTY motif is required for SAPP $\alpha$-mediated Akt signaling. Next, we investigated the possible contribution of the APP C-terminal

\section{a}
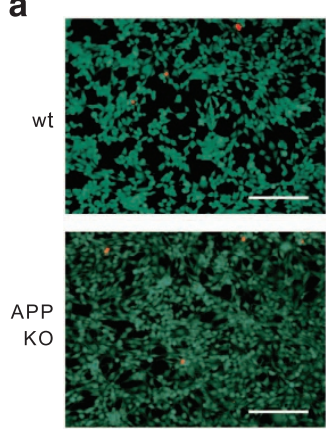

$+\mathrm{FCS} /+$ Gluc
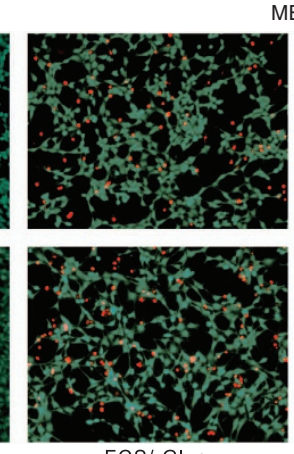

-FCS/-Gluc

b

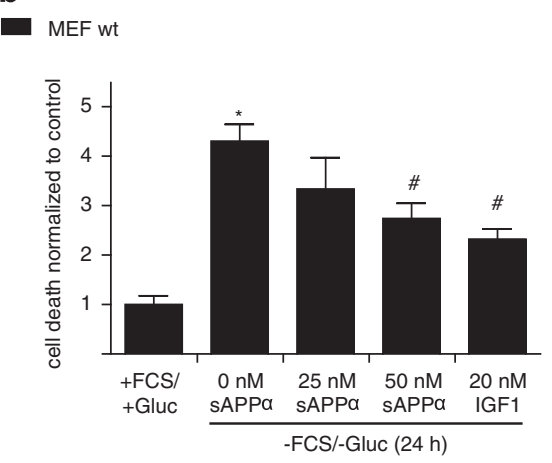

MEFs
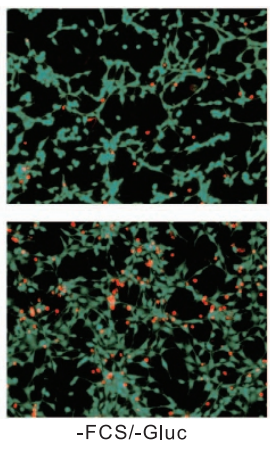

+50 nM SAPPa
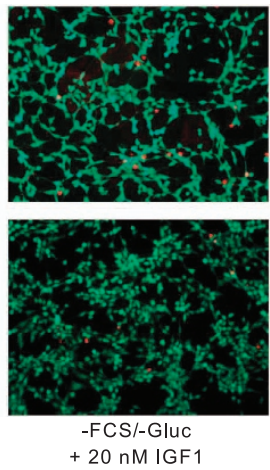

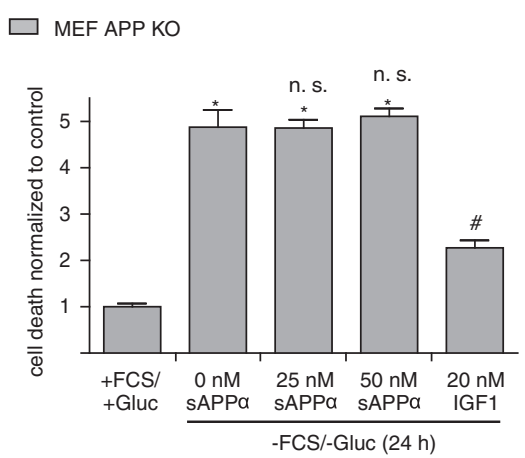

Figure 2 SAPP $\alpha$-mediated suppression of cell death depends on the presence of holo-APP. (a) MEFs prepared from wt or APP-KO mice were cultured in glucose- and serum-free medium for $24 \mathrm{~h}$ to induce cell death. In parallel, cells were treated with yeast-derived SAPP $\alpha$ or IGF1 as a positive control. Cells were stained with greenfluorescent calcein-AM to indicate intracellular esterase activity. This dye exclusively stains live cells (green). Cultures were simultaneously stained with red fluorescent ethidium homodimer-3 to visualize loss of plasma membrane integrity (red, dead cells). Scale bar: $500 \mu \mathrm{m}$. (b) MEFs obtained from wt (left panel) or APP-KO mice (right panel) were cultured in glucose- and serum-free medium for $24 \mathrm{~h}$ and treated with the indicated amounts of SAPP $\alpha$ or IGF. PI-stained cells were analyzed with a FACS cytometer and the extent of cell death was normalized to control cells $(+\mathrm{FCS} /+\mathrm{Gluc})$. Data are means from four cultures \pm S.E.M. Statistical significance: ${ }^{*} P<0.05$ compared with controls $\left(+\mathrm{FCS} /+\right.$ Gluc); ${ }^{\#} P<0.05$ compared with serum/glucose withdrawal in the absence of SAPP $\alpha / E 1 / I G F 1 ; N S=$ not significant

Figure $3 \mathrm{sAPP} \alpha$ induces neuroprotection in organotypic hippocampal slices from wt mice but not from APP-deficient mice. (a) Representative light microscopic image of a hippocampal slice culture. (b) Organotypic hippocampal slices dissected from wt or APP-deficient (APP-KO) mice were cultured on permeable membrane inserts in full medium containing $5 \%(\mathrm{~V} / \mathrm{v}$ ) horse serum and glucose. After 5 days in vitro (DIV), slices were transferred into serum- and glucose-free neurobasal A medium with $25 / 50 \mathrm{nM}$ SAPP $\alpha$ or $20 \mathrm{nM} \mathrm{IGF1}$ for $24 \mathrm{~h}$. Cell death was visualized microscopically by PI staining. Whole slices are shown in the upper panel of each genotype; magnification: $\times 4$; scale bar: $400 \mu \mathrm{m}$. A representative area in the CA1 region of the hippocampus (as depicted in the white square) is shown in the lower panel of each genotype; magnification: $\times 20$; scale bar: $100 \mu \mathrm{m}$. (c) Organotypic slices from wt mice subjected to serum/glucose deprivation in the presence of the ADAM10 ( $\alpha$-secretase) inhibitor Gl254023X show increased PI staining in comparison with serum/glucose-deprived controls, which is rescued by recombinant SAPP $\alpha$ ( $50 \mathrm{nM})$. (d) Extent of cell death in wt versus APP-KO slices and slices treated with ADAM10 inhibitor was calculated by counting PI-stained (dead) cells in a specified area in the CA1 region and subsequent normalization to serum-/glucose-treated controls. Data are means from four to six cultures \pm S.E.M. Statistical significance: ${ }^{*} P<0.05$ compared with controls $(+\mathrm{HS} /+\mathrm{Gluc}) ;{ }^{\#} P<0.05$ compared with serum/glucose withdrawal + dimethyl sulfoxide (DMSO) or ADAM10 inhibitor in the absence of SAPP $\alpha$ 
a

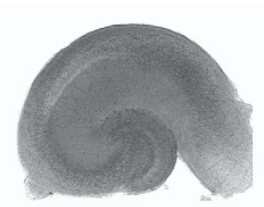

b

+HS/+Gluc

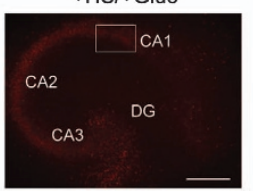

wt
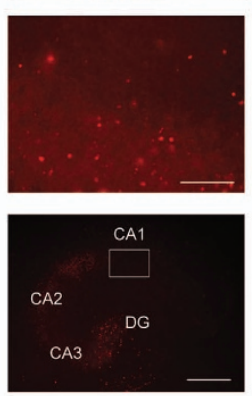

APP KO

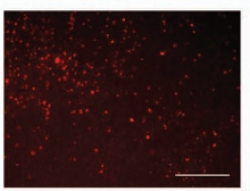

C
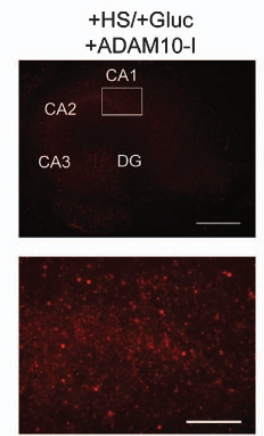

-HS/-Gluc
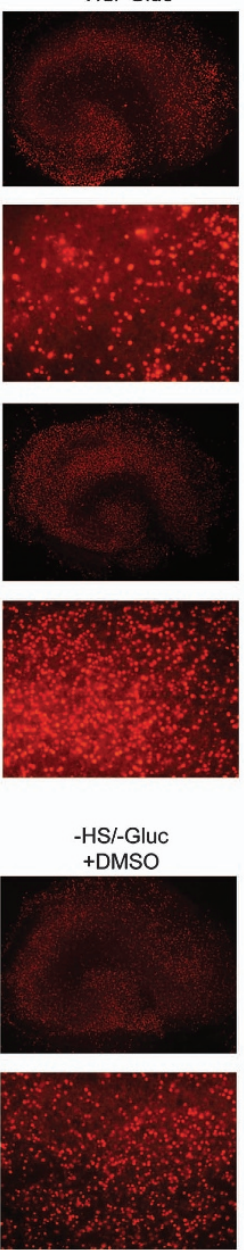

S/-Gluc
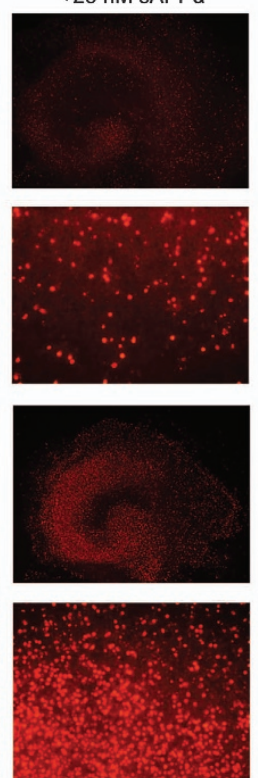

-HSI-Gluc +ADAM10-I
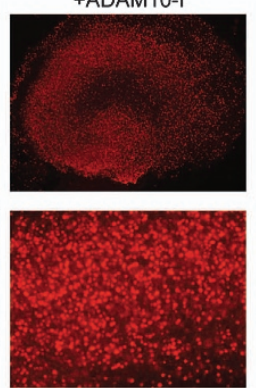

-HS/-Gluc $+50 \mathrm{nM}$ sAPPa
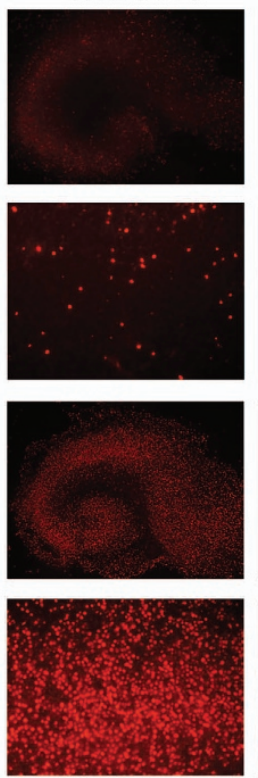

-HS/-Gluc +ADAM10-I $+50 \mathrm{nM}$ sAPPa
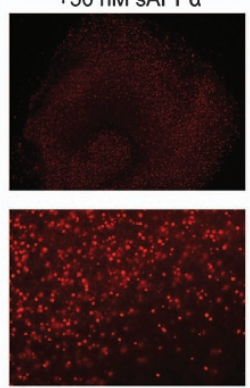

d

\section{PI positive cells in the CA1 region} wt

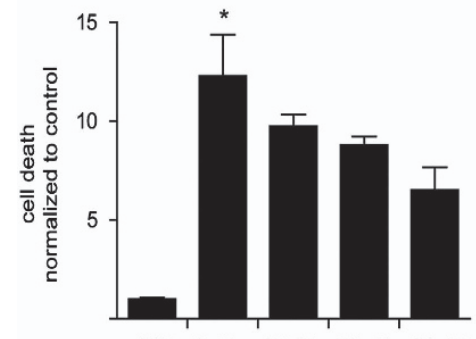

+HSI $0 \mathrm{nM} \quad 25 \mathrm{nM} \quad 50 \mathrm{nM} \quad 20 \mathrm{nM}$ +Gluc SAPPa SAPPa SAPPa IGF1 -HSI-Gluc (24 h)

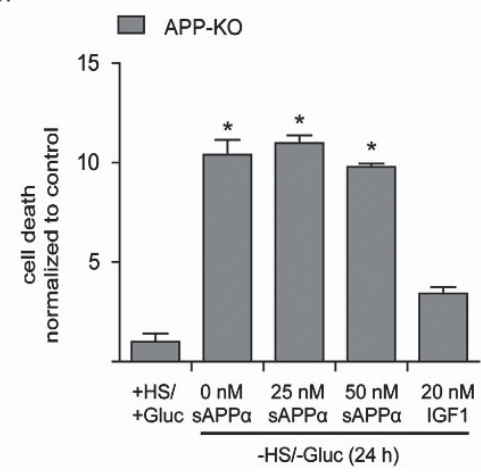

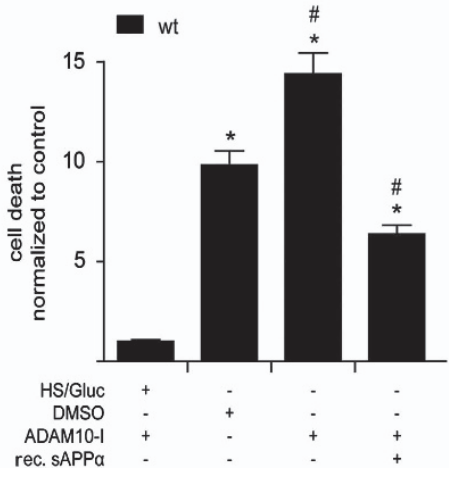


domain for SAPP $\alpha$-induced Akt activation. To this end, we expressed a lentiviral construct encoding the extracellular part from the amino terminus to the $\beta$-secretase cleavage site (SAPP $\beta$ ) of APP coupled to the platelet-derived growth factor receptor (PDGFR) transmembrane domain (TM) in MEF APP-KO cells (Figure 6a). This construct a

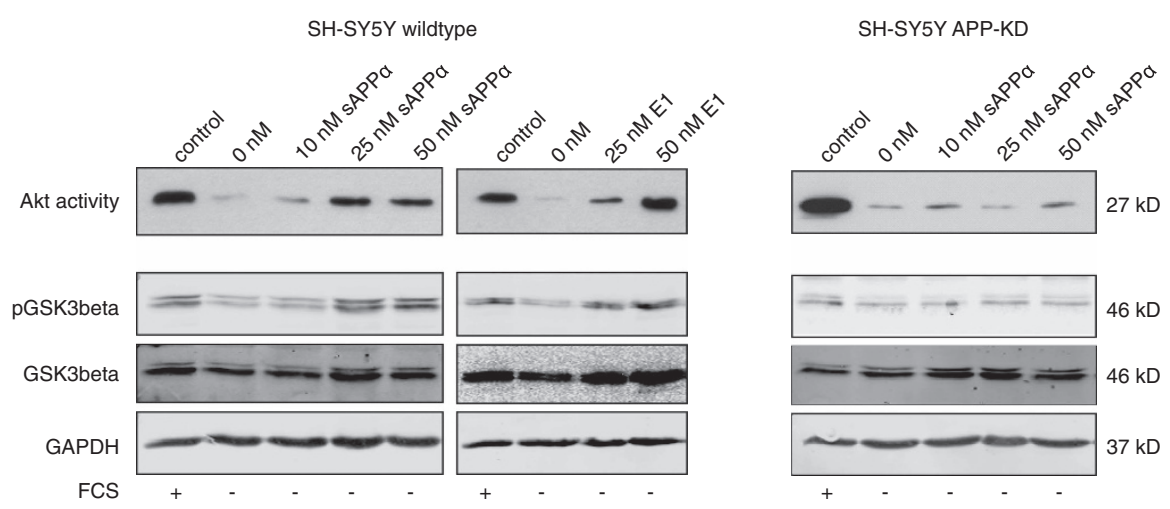

b

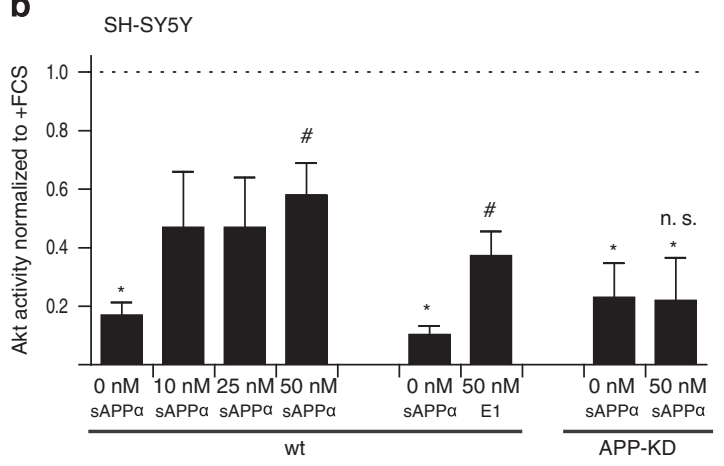

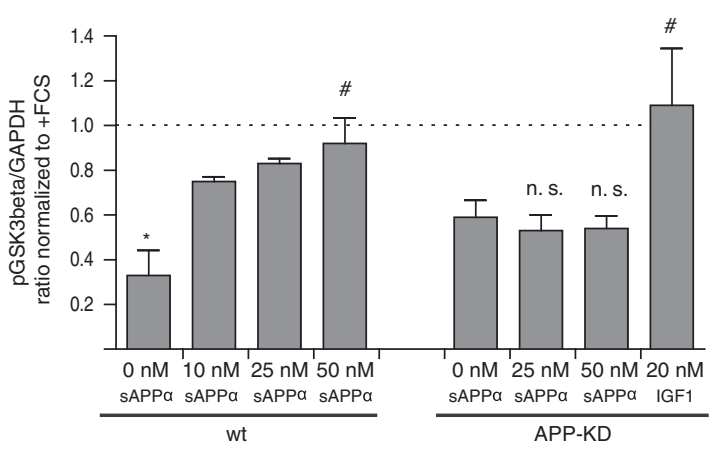

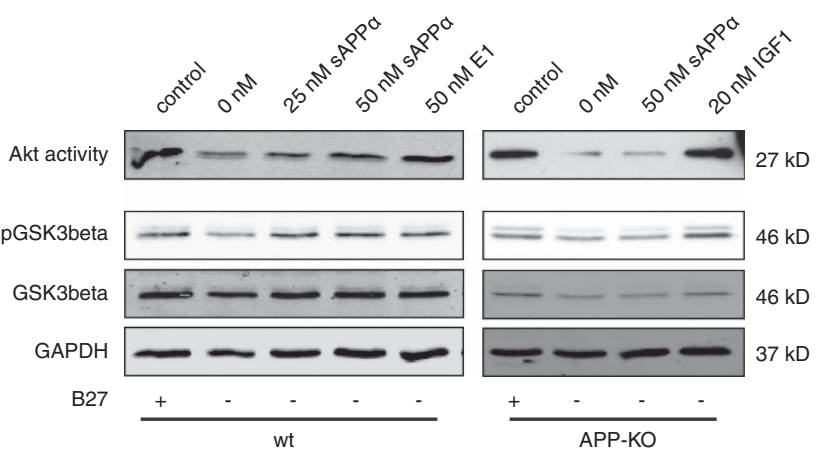
hippocampal neurons d
C SH-SY5Y APP-KD retransfected with APP
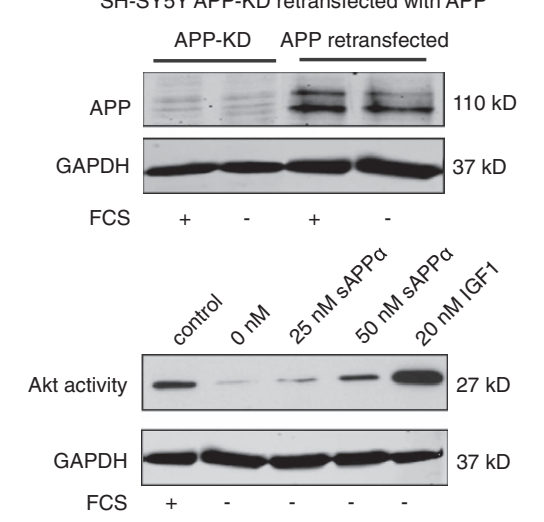

e
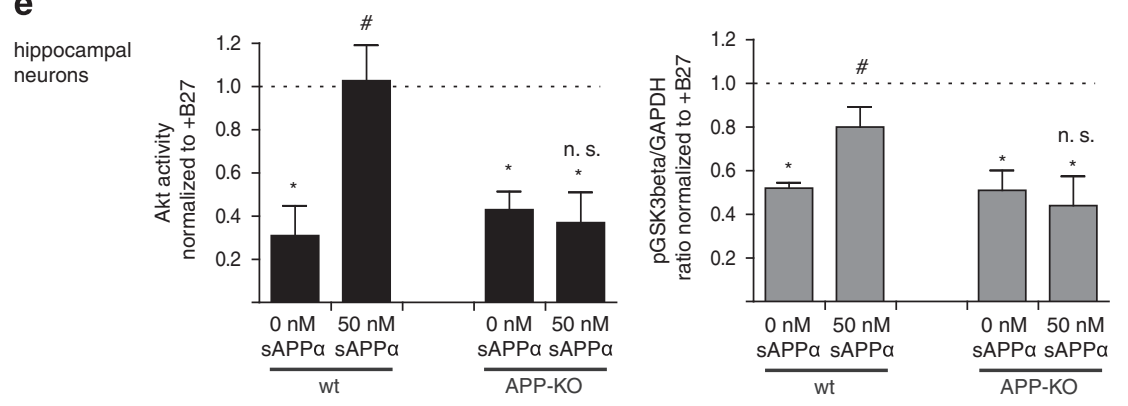
(sAPP $\beta$-PDGFR-TM) lacks the complete APP C-terminal domain. Similar to SH-SY5Y cells and neurons, significant SAPP $\alpha$-dependent induction of Akt activity under serum deprivation was also observed in MEF wt cells (Supplementary Figure 1A). However, as presented in Figure $6 b$ (left panel), sAPP $\alpha / E 1$ were not able to activate the Akt pathway in the absence of the APP C-terminal domain as determined by conventional western blots or in vitro kinase assays. To further delineate the domain within the APP C-terminus that mediates Akt activation, we tested primary hippocampal neurons from APP- $\triangle \mathrm{CT} 15$ mice. These lack the last $15 \mathrm{C}$-terminal amino acids (aa) of APP, including the YENPTY motif ${ }^{41}$ that interacts with several adaptor proteins including Fe65 and is crucial for transcriptional activation by the (released) APP intracellular domain (AICD). ${ }^{42}$ We found that Akt signaling was potently activated in these cells, despite the absence of the YENPTY motif (Figure 6b, right panel) excluding
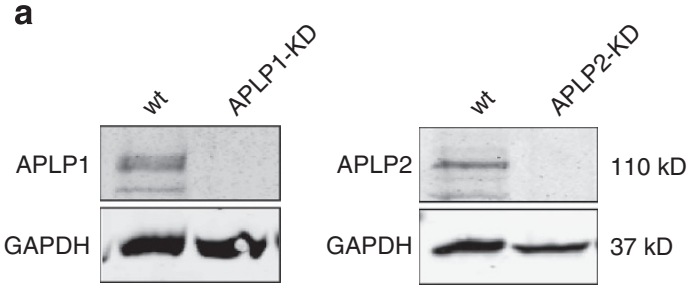

b

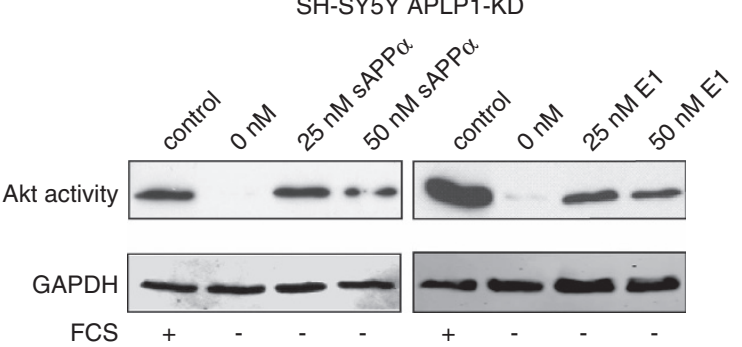

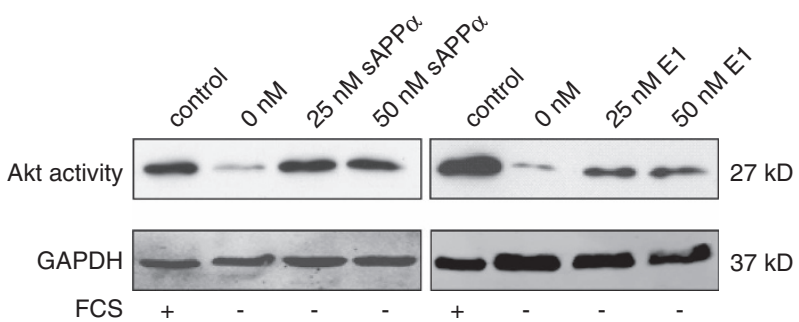

d $\square$ SH-SY5Y APLP1-KD

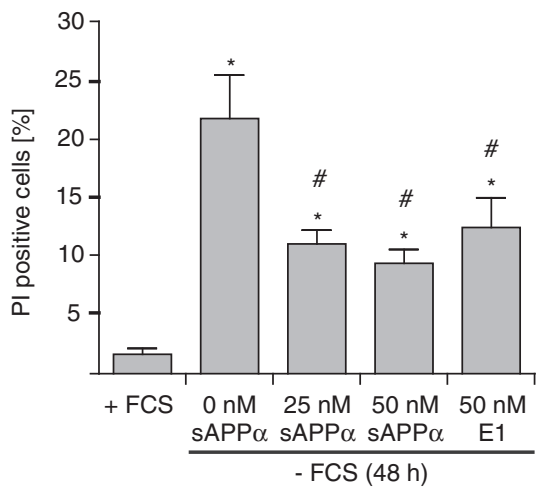

e

SH-SY5Y APLP2-KD 
AICD-mediated effects on transcription as the underlying cause of $\operatorname{sAPP} \alpha$-dependent Akt signaling. Quantification of protein levels confirmed significant Akt activity induction in APP- $\triangle \mathrm{CT} 15$ mice as compared with MEF cells expressing SAPP $\beta$-PDGFR-TM in an APP-deficient background (Figure 6b, graphs).

a
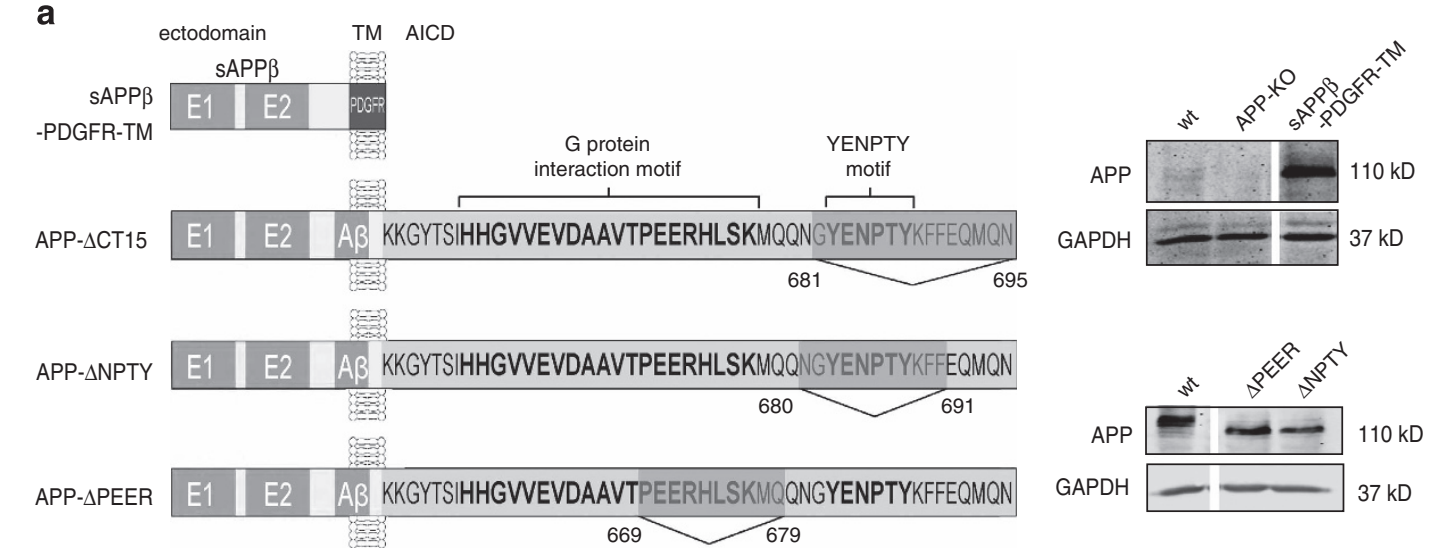

b
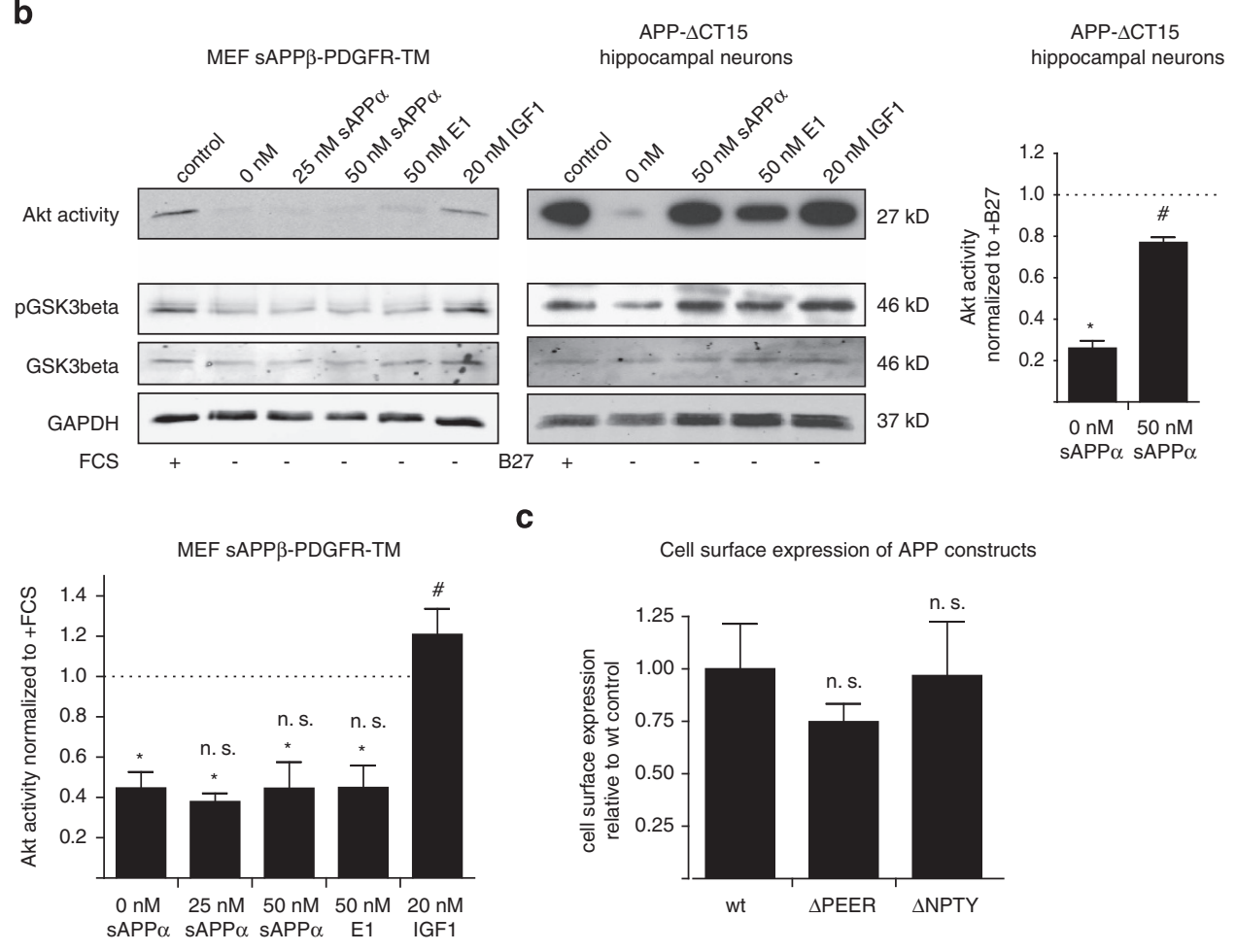

Cell surface expression of APP constructs

d
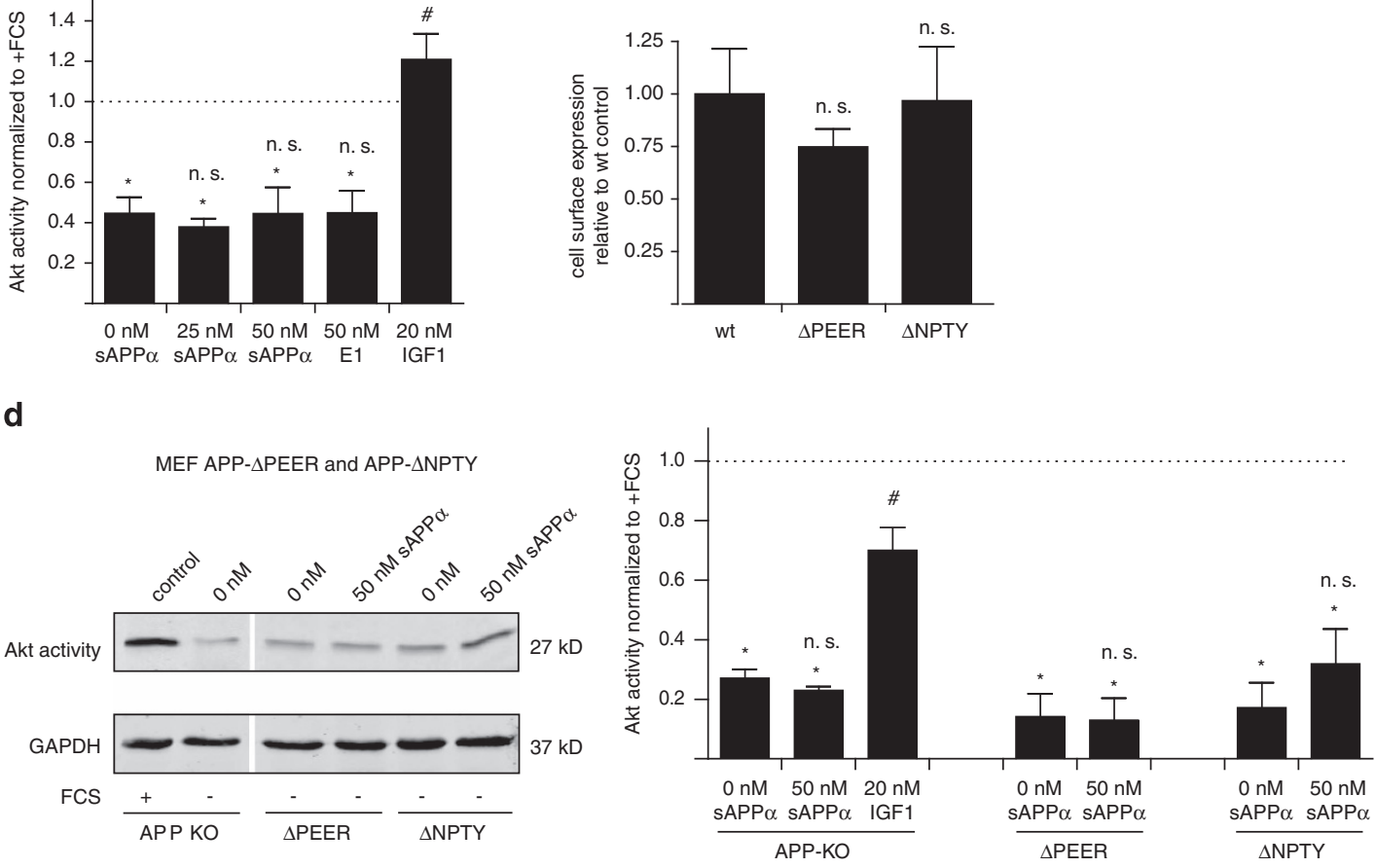
Activation of the PI3K/Akt pathway by $S A P P \alpha / E 1$ is mediated by G-protein-dependent signaling. To further map the regions of the APP $\mathrm{C}$-terminal domain required for SAPP $\alpha$-induced Akt activation, we transfected two APP deletion mutants (illustrated in Figure 6a) lacking the YENPTY motif ( $\triangle$ NPTY) or a central sequence motif $(\triangle P E E R)$ of the APP C-terminal domain ${ }^{43,44}$ into an APP-deficient background. The $\triangle$ PEER mutant lacks the membrane-proximal G-protein binding site. ${ }^{2,45}$ Transfection efficiency and overall expression of the APP constructs was verified by western blot (Figure 6a). We also applied an on-cell-Western approach to quantify their cell surface expression after transfection in comparison with wt control cells. As shown in Figure 6c, cell surface expression levels of both constructs were comparable with those detected in wt cells. In line with the result obtained in $\triangle \mathrm{CT} 15$ neurons, Akt signaling was strongly activated in $\triangle \mathrm{NPTY}$-transfected cells (Figure 6d). In contrast, expression of the $\triangle$ PEER mutant, despite being expressed at similar levels as APP $\triangle$ NPTY, did not rescue activation of the Akt pathway (Figure 6d). This suggests that Akt pathway activation by $\operatorname{sAPP} \alpha$ requires G-protein-mediated signaling. Indeed, applying pertussis toxin (PTX), a specific G-protein inhibitor, efficiently blocked sAPP $\alpha$-mediated Akt signaling in wt MEFs (Figure 7a), which was readily confirmed in blot quantifications (Figure $7 a$, graph). We also performed FACS analysis with MEF wt cells simultaneously treated with SAPP $\alpha$ and PTX or the PI3K inhibitor LY294002 to quantify cell death of cultures under serum/glucose deprivation. As depicted in Figure $7 \mathrm{~b}$, treatment both with PTX and the PI3K inhibitor completely abolished $\operatorname{sAPP} \alpha$-mediated cell survival. This observation further substantiates our findings with APP deletion constructs that $S A P P \alpha$ initiates cell survival via G-proteinmediated activation of the PI3K/Akt pathway.

\section{Discussion}

Previous studies from our and other labs suggested that SAPP $\alpha$ exerts potent neuroprotective effects, whereas the amyloidogenic pathway of APP processing and AICD have largely been linked to neurodegeneration and apoptosis. $^{32,46,47}$ Despite the fact that this apparent dichotomy of APP-dependent biologic effects was proposed several years ago, the overwhelming part of existing experimental work has been devoted to decipher the pathophysiologic, neurotoxic roles of APP. Therefore, the molecular mechanisms of SAPP $\alpha$-mediated neuroprotection have not been clearly established so far. ${ }^{32}$ Our data from the present study unequivocally demonstrate that recombinant $\operatorname{SAPP} \alpha$ is capable of providing a robust neuroprotection. In line with the observation that synthetic inhibitors of PI3K can abrogate sAPP $\alpha$-dependent neuroprotection, ${ }^{37-39}$ they also provide first direct evidence that $\operatorname{SAPP} \alpha$ indeed represents a key activator of the PI3K/Akt survival signaling pathway.

It is clearly established that holo-APP can homodimerize, ${ }^{10}$ but the cellular receptor coupling $S A P P \alpha$ to downstream survival signaling was hitherto unidentified. In another study, APP dimers were proposed to exert a proapoptotic function, which in turn is antagonized by SAPP $\alpha$ in B103 neuroblastoma cells. ${ }^{23}$ Despite the somewhat different conclusions drawn by the authors and the fact that SAPP $\alpha$-dependent intracellular signaling events were not addressed in that study, its principal finding, that is, that APP is required for the antiapoptotic effect of $\operatorname{sAPP} \alpha$, is in line with our own observations. Recently, Jimenez et al. ${ }^{48}$ also demonstrated that $\operatorname{SAPP} \alpha$ can limit induction of the GSK3 $\beta$ stress signaling pathway. Based on experimental evidence exclusively obtained with pharmacologic inhibitors (which often exhibit a limited target specificity and thereby make interpretation of results difficult), this study also suggests that $\mathrm{sAPP} \alpha$-dependent neuroprotection may require the IGF-1 receptor and the insulin receptor (IR) to mediate its effects. The authors proposed a model in which SAPP $\alpha$ acts through IGF-1 and/or IRs to induce the PI3K/Akt pathway and to phosphorylate and inhibit the activity of GSK$3 \beta .^{48}$ Despite the proposed contribution of coreceptors such as IR and insulin-like growth factor 1 receptor (IGF1-R), our own experiments in IGF1-R-deficient cells did not confirm a role of IGF1-R in SAPP $\alpha$-mediated neuroprotection (unpublished data). However, our data obtained in this study clearly demonstrate that in the absence of endogenous holo-APP, Akt activation by $\mathrm{SAPP} \alpha$ is completely abolished. Our data also suggest that the $\mathrm{E} 1$ domain alone can substitute for SAPP $\alpha$ in rescuing the activity of the Akt pathway under conditions of serum deprivation. This could not be observed in APP-depleted cells, emphasizing that the E1 domain, containing the growth factor-like domain, encompasses the neuroprotective active part of SAPP $\alpha$. Surprisingly, we and others have previously demonstrated that $\operatorname{SAPP} \beta$, which is generated via $\beta$-secretase cleavage of APP, lacks the neuroprotective properties of $\operatorname{SAPP} \alpha .^{37,49}$ Given the fact that $\operatorname{SAPP} \beta$ also carries the E1 domain, this lack of neuroprotective properties of $\operatorname{SAPP} \beta$ versus $\operatorname{SAPP} \alpha$ is currently difficult to

Figure 6 Akt pathway activation requires the APP C-terminal domain, but not the YENPTY motif of APP. (a) Schematic illustration of mutant APP constructs used. The two APP C-terminal domain mutants, APP- $\triangle$ PEER and APP- $\triangle$ NPTY, have been described before. ${ }^{44}$ Expression of the SAPP $\beta$-PDGFR-TM construct and the two APP C-terminal domain mutants was confirmed in a western blot (right panel). (b, left panel) MEF APP KO cells were transduced with a lentiviral construct encoding sAPP $\beta$ fused to the PDGFR TM. No sAPP $\alpha$-induced Akt activity was observed, suggesting that the APP C-terminal domain is necessary for this effect. (b, right panel) Activation of Akt signaling by SAPP $\alpha$ and the $\mathrm{E} 1$ domain in hippocampal neurons from mice lacking the $15 \mathrm{C}$-terminal aa of APP $(\Delta C T 15)$. In parallel to Akt activity detection, whole-cell lysates were tested with anti-pGSK3 $\beta$, anti-GSK3 $\beta$ and anti-GAPDH (loading control) antibodies. Both graphs show the respective blot quantification normalized to serum-treated controls (dashed line). Data are means \pm S.E.M. from three blots. Statistical significance: ${ }^{*} P<0.05$ compared with controls $(+F C S /+B 27)$; ${ }^{*} P<0.05$ compared wth serum withdrawal in the absence of $\mathrm{SAPP} \alpha / \mathrm{E} 1 / \mathrm{IGF} 1$; NS $=$ not significant. (c) Cell surface expression of the two APP C-terminal domain mutants after transfection relative to wt APP expression levels. Fluorescence signals measured in an on-cell-Western with unpermeabilized cells were normalized to background staining. Data are means \pm S.E.M. from three experiments. Statistical significance: NS = not significant compared with wt control. (d) APP- $\triangle P E E R$ and $\triangle N P T Y$ were transfected into MEF APP-KO cells. Recombinant SAPP $\alpha$ activated Akt in serum-deprived wt and $\triangle \mathrm{NPTY}$ cells, but not in $\triangle \mathrm{PEER}$ lacking an interaction motif for $\mathrm{G}$ proteins. Blot quantification values were normalized to serum-treated controls (dashed line). Data are means \pm S.E.M. from three blots. Statistical significance: ${ }^{*} P<0.05$ compared with controls ( + FCS/ + B27); ${ }^{\#} P<0.05$ compared with serum withdrawal in the absence of SAPP $\alpha / E 1 / / G F 1 ; N S=$ not significant 
a $\quad$ MEF $w t+$ G protein inhibitor (PTX)
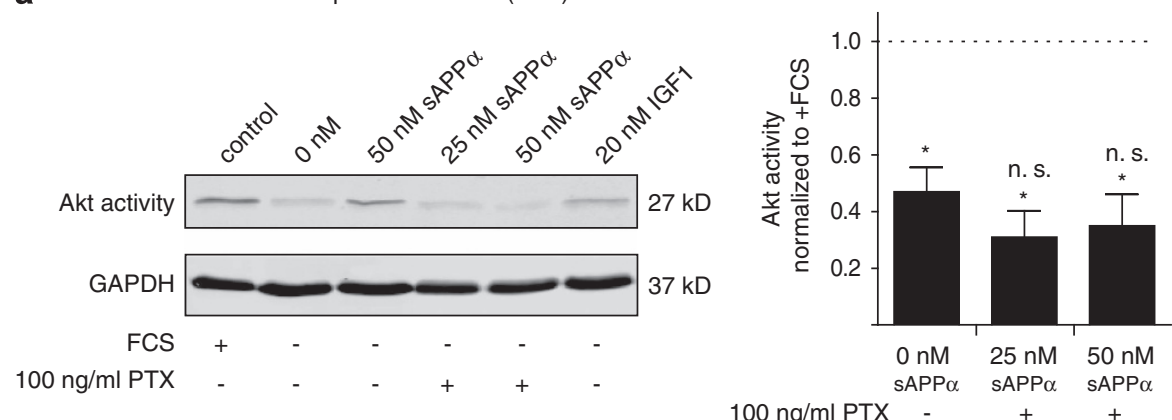

b

Cell survival with G protein (PTX) and PI3K inhibitor (LY294007)

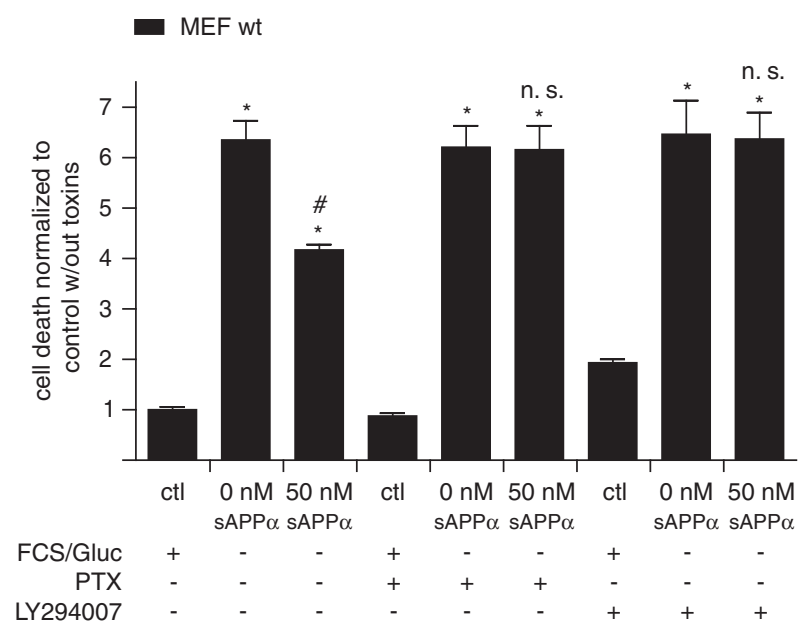

Figure 7 sAPP $\alpha$-dependent activation of the PI3K/Akt is mediated by G-protein-dependent signaling. (a) MEF wt cells preincubated with $100 \mathrm{ng} / \mathrm{ml}$ PTX, a specific G-protein inhibitor, showed no induction of Akt activity by SAPP $\alpha$. Blot quantifications ( $n=3$ blots \pm S.E.M.) confirmed these results (graph). Values were normalized to serumtreated controls (dashed line). Statistical significance: ${ }^{*} P<0.05$ compared with control ( + FCS); NS $=$ not significant. (b) FACS analysis with MEF wt cells treated with PTX $(100 \mathrm{ng} / \mathrm{ml}, 24 \mathrm{~h})$ or PI3K inhibitor $(10 \mu \mathrm{M}, 24 \mathrm{~h})$ abolished sAPP $\alpha$-mediated cell survival under serum/glucose deprivation. Values are normalized to serum/glucose-treated control without inhibitors. Data are means from four cultures \pm S.E.M. Statistical significance: ${ }^{*} P<0.05$ compared with controls $(+\mathrm{FCS} /+\mathrm{Gluc}) ;{ }^{\#} P<0.05$ compared with serum/glucose withdrawal in the absence of $\operatorname{sAPP} \alpha ; N S=$ not significant

understand, but may involve conformational differences between these two molecules. Future studies will have to address this important topic of APP biology in more detail.

In line with our findings on the GSK3 $\beta$-regulating function of $\operatorname{sAPP} \alpha$, GSK $3 \beta$ activity has been found to be upregulated in the AD brain. ${ }^{48,50}$ These investigations support the hypothesis that the aging-associated decline of $\operatorname{sAPP} \alpha$ and its neuroprotective function ${ }^{5,7,32}$ may contribute to this upregulation, thereby sensitizing neurons to apoptosis. Based on this notion, we hypothesize that the shift toward amyloidogenic APP processing (promoting enhanced generation of $A \beta$ ) and loss of the SAPP $\alpha$-dependent function in neuroprotection may synergize in rendering neurons more prone to neurodegeneration in the aging brain.

In light of the high structural similarity between APP and APLPs, ${ }^{2}$ we hypothesized that APLP1 and APLP2 may possess similar or overlapping physiologic functions as APP in neuroprotection. It is well established that APP and APLPS can form homo- and heterodimers, arguing for a functional connection between these molecules. ${ }^{10}$ APLP1 and APLP2 do not contain an $A \beta$ domain, but their ectodomains are shed in an ADAM10-dependent manner similar to APP. ${ }^{51,52}$ In line with this hypothesis, neuroprotective IGF-1 signaling induces antiamyloidogenic processing of APP and ectodomain shedding of APLP1 and APLP2 in human SH-SY5Y neuroblastoma cells. ${ }^{53}$ To analyze the potential role of APLP1 and APLP2 in SAPP $\alpha$-mediated neuroprotection, we also established stable lentiviral KDs in SH-SY5Y cells. Our data clearly demonstrate that APP, but not APLP1 and APLP2, specifically functions as a surface receptor for $\operatorname{sAPP} \alpha-$ mediated neuroprotection.

Our observation that endogenous APP was required for SAPP $\alpha$-mediated neuroprotection suggested a signaling role of the APP C-terminal domain and its interactors in this context. In an alternative scenario, we hypothesized that membrane tethering of APP alone may suffice for sAPP $\alpha$-mediated activation of the Akt pathway. To further characterize the functional domains of holo-APP required for SAPP $\alpha$-mediated signaling, we used a construct composed of the E1 and E2 domains of APP fused to the heterologous PDGFR TM. We then overexpressed this construct in an APP-KO background. However, it was not able to restore 
sAPP $\alpha$-mediated Akt activation under serum deprivation, indicating that the APP $\mathrm{C}$-terminal domain is indeed required for neuroprotection.

The APP C-terminal domain couples APP to diverse intracellular signaling pathways. It was proposed that the Src homology 2 domain of Abl or the phosphotyrosine-binding domain (PTBD) of Shc may interact with the YENPTY motif of APP. This would suggest a role for APP in tyrosine kinasemediated signal transduction. ${ }^{54}$ Consequently, to further investigate the putative role of YENPTY interactors, we used primary neuron cultures of APP $\triangle \mathrm{CT}$ mice (lacking the 15 C-terminal aa of APP) to investigate the possible contribution of PTBD-containing interactors to $\operatorname{SAPP} \alpha$-mediated Akt activation. Intriguingly, our data show that the last C-terminal 15 aa of the APP C-terminal domain are dispensable for mediating the neuroprotective effect of $\operatorname{SAPP} \alpha$. This domain comprises the YENPTY motif to which the vast majority of the APP C-terminal domain interactors bind. ${ }^{2}$

Our finding that the APP C-terminal domain, but not the YENPTY motif, is essential for mediating SAPP $\alpha / A P P$-induced neuroprotection suggested that YENPTY-independent interactors are required for SAPP $\alpha$-induced neuroprotection. Indeed, the heterotrimeric G-protein subunit $\mathrm{G} \alpha(\mathrm{S})$, which binds in a YENPTY motif-independent manner to the APP C-terminal domain, was recently shown to be involved in APP-mediated modulation of GSK3 $\beta$ and neurite outgrowth. ${ }^{45}$ To further map the APP C-terminal domain region mediating SAPP $\alpha$-dependent neuroprotection, we reconstituted APP$\mathrm{KO}$ cells with a deletion mutant ( $\triangle \mathrm{PEER}$ ) lacking the G-protein interaction motif. ${ }^{45,55}$ In contrast to the $\triangle$ NPTY mutant, expression of the $\triangle$ PEER mutant ${ }^{43,44}$ did not rescue SAPP $\alpha$ induced Akt activation after serum starvation, indicating that the G-protein-mediated signaling is causally involved. Consistently with these data, the G-protein inhibitor PTX completely abolished SAPP $\alpha$-induced Akt activation and cell survival. Of note, G-protein-dependent activation of the $\mathrm{PI}$ KK/Akt pathway has been previously demonstrated in different cell models. ${ }^{56,57}$

In conclusion, we were able to identify key signaling components and mechanisms involved in SAPP $\alpha$-mediated neuroprotection: our data indicate that $\operatorname{SAPP} \alpha$ signals either by direct binding or via an indirect mechanism through membranetethered APP. As APP harbors a G-protein interaction domain and $\operatorname{SAPP} \alpha$-mediated neuroprotection is lost upon deletion of this motif, this strongly suggests that APP serves as a receptor to trigger G-protein-dependent activation of PI3K. This activation leads to the recruitment and downstream activation of the prosurvival kinase Akt and subsequent inhibition of its proapoptotic target GSK3 $\beta$ (Figure 8). These findings support the hypothesis that SAPP $\alpha$ and holo-APP share equal relevance in mediating the neuroprotective function of APP. They also provide novel mechanistic insights into the physiologic function of APP in limiting neuron damage and death in response to neurotoxic stress conditions, as well as the loss of this function during brain aging.

\section{Materials and Methods}

Materials. Unless stated otherwise, cell culture media and supplements were purchased from Invitrogen (Darmstadt, Germany), human IGF1 from Sigma-Aldrich (Seelze, Germany) and Millicell cell culture inserts $(0.4 \mu \mathrm{m}, 30 \mathrm{~mm}$

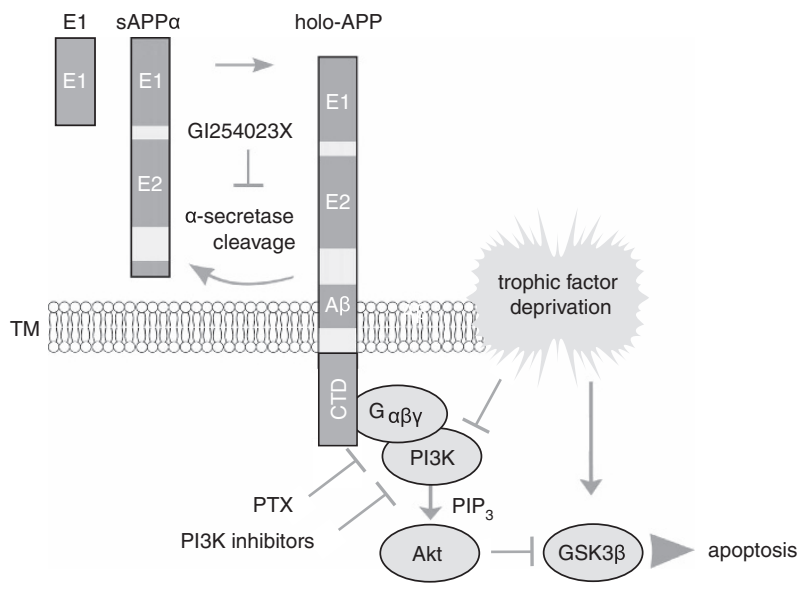

Figure 8 Hypothetical model of SAPP $\alpha$-mediated Akt activation and survival signaling. In the anti-amyloid processing pathway, APP is cleaved by $\alpha$-secretase generating SAPP $\alpha$ that can activate induction of the PI3K/Akt survival pathway. This activation depends on the presence of holo-APP and its intracellular G-protein interaction motif, coupling SAPP $\alpha$ to G-protein-dependent induction of PI3K/Akt and downstream suppression of GSK3 $\beta$, thereby preventing apoptosis. CTD: APP C-terminal domain

diameter) for hippocampal slice cultures from Merck Millipore (Darmstadt, Germany). PTX and LY294007 were purchased from Enzo Life Sciences (Lörrach, Germany). All other biochemicals and chemicals were provided in analytical grade purity from Roth (Karlsruhe, Germany) or Sigma-Aldrich. Plasticware was purchased from Corning Life Sciences (Wiesbaden, Germany) or Greiner Bio-One (Frickenhausen, Germany).

Cell and tissue culture. Immortalized MEFs were derived from wt or APP-KO mice. ${ }^{58}$ Hippocampal neurons and organotypic slices were dissected from the same mice. SH-SY5Y cells were cultured in Dulbecco's modified Eagle's medium (DMEM) with F-12 Nutrient Mixture (Ham) supplemented with $10 \%$ fetal calf serum (FCS), $2 \mathrm{mM}$ L-glutamine, $100 \mathrm{U} / \mathrm{ml}$ penicillin and $100 \mu \mathrm{g} / \mathrm{ml}$ streptomycin (pen/strep). MEFs were grown in DMEM supplemented as above. Organotypic (hippocampal) slice cultures were prepared from P4 to 6 transgenic and non-transgenic littermate mouse pups as described in Stoppini et al. ${ }^{59}$ and cultured on cell culture inserts (interface method). Broken or otherwise lesioned slices were discarded. Slices were maintained in culture medium containing $45 \%$ minimum essential medium, 25\% basal medium Eagle, $25 \%$ horse serum (HS), $3 \%$ glucose $(20 \%), 1 \%$ L-glutamine, $0.5 \%$ pen/strep and $0.5 \%$ fungizone, adjusted to $\mathrm{pH} 7.2$, and kept at $5 \% \mathrm{CO}_{2}$ and $37^{\circ} \mathrm{C}$. Culture medium was changed every 2-3 days. For cell death experiments, the culture medium was replaced with glucose-free neurobasal A medium without HS (full medium as control) after 5-6 days in vitro. Until then, slices had shrunk from $400 \mu \mathrm{m}$ thickness to $\sim 200 \mu \mathrm{m}$. PI stain $(0.8 \mu \mathrm{g} / \mathrm{ml})$ was directly added to the medium before microscopic evaluation. Primary hippocampal neurons were dissociated from hippocampal slices obtained from $\mathrm{P} 1$ to 3 pups and plated into full medium (neurobasal $\mathrm{A}$ medium supplemented with $2 \%$ B27, $2 \%$ GlutaMAX, $0.2 \%$ pen $/$ strep, $1 \%$ gentamycin) on poly-D-lysine-coated plates. Neurons were maintained at $5 \% \mathrm{CO}_{2}$ and $37^{\circ} \mathrm{C}$ for 7 days before experiments.

Animals. All mice were bred and maintained according to the FELASA and National Animal Experimental Ethics Committee Guidelines. We used wt, APP-KO $\left(\mathrm{APP}^{-1-}\right.$ ) and APP- $\triangle \mathrm{CT} 15 \mathrm{C} 57 \mathrm{BI} / 6$ mice ${ }^{41,58}$ APP-KO mice lack membraneanchored full-length APP and all of its proteolytic fragments; APP- $\triangle \mathrm{CT} 15$ mice lack the last 15 aa of the C-terminus of APP, which includes the YENPTY motif. APP-KO and APP- $\triangle$ CT15 mice had been backcrossed for at least six generations to $\mathrm{C} 57 \mathrm{~B} / / 6$ mice.

Viral vectors and plasmids. Stable APP/APLP1/APLP2 KDs were achieved by transducing wt SH-SY5Y cells with lentiviral particles to stably express shRNAs directed against huAPP or huAPLPs. Mission shRNA Plasmid 
DNA containing the pLKO.1-puro vector was purchased from Sigma-Aldrich (clone IDs for APP: NM_000484.2-3202s1c1; APLP1: NM_005166.2-1711s1c1 and APLP2: NM_001642.1-1582s1c1). Packaging (psPAX2) and enveloping (pMD2.G) plasmids were from Addgene (Cambridge, MA, USA). Production of lentiviral particles was performed following Addgene's pLKO.1 TRC Cloning Vector Protocol (2006). Lentiviral vectors encoding the fusion protein SAPP $\beta$-PDGFR-TMD were generated by triple transfection of HEK-293T cells with the envelope plasmid pMD2.G, the packaging plasmid pCMV $\triangle$ R8.9 and the transfer vector plasmid pHAIN as described. ${ }^{60}$ The plasmid pHAIN encodes human SAPP $\beta$ under control of the CMV promoter fused at its N-terminus to the HA tag and the $\lg G$ signal peptide. At the $\mathrm{C}$-terminus, $\operatorname{SAPP} \beta$ had been fused to a myc tag followed by the TM of the PDGFR as provided by the pDisplay plasmid (Invitrogen). Thus, upon transduction with this vector, MEFs expressed the extracellular part of APP but not its TM. The APP mutant constructs lacking the YENPTY motif ( $\triangle$ aa $680-691$ of APP695) or the G-protein interaction motif ( $\triangle$ aa $669-679$ ) have been described before ${ }^{44}$ and were subcloned in-frame from pUAS into pCDNA3.1 behind the N-terminal myc tag. ${ }^{43}$ Plasmids were purified with the Plasmid Maxi Kit from Qiagen (Hilden, Germany) and commercially sequenced to confirm the mutations. Transfection of MEF APPKO cells with APP constructs was performed with FuGENE HD Transfection Reagent (Roche Diagnostics, Mannheim, Germany) according to the manufacturer's instructions and verified in a western blot.

Purification of recombinant SAPP $\alpha / E 1$ domain. The coding sequences of SAPP695 $\alpha$ (aa 18-611) and APP-E1 (aa 18-189) were cloned in frame as $6 \times$ His-tagged fusions in a pBLHIS-SX-derived expression vector and expressed in Pichia pastoris GS115 cells. The asparagine residue at position 467 of APP695 (glycosylation site) was replaced with serine by site-directed mutagenesis. The yeast was cultured in buffered glycerol complex medium with peptone. Addition of methanol induced the expression of 6-His-tagged SAPP $\alpha / E 1$ and secretion into the surrounding medium. The proteins were isolated with Nisepharose beads or Ni-affinity chromatography (HPLC) from the medium and eluted with imidazole. Their biologic, neuroprotective activity was verified in several control experiments with different cell lines under proteasomal stress or serum deprivation (data not shown).

Cell death and viability assays. Cell death was quantified based on plasma membrane permeabilization. To this aim, cells or tissue cultures were cultured under normal serum conditions (control) and serum/trophic factor deprivation ( - FCS/ - B27/ - HS) or double deprivation with additional removal of glucose ( - FCS/ - Gluc) for 24-48 h. Cultures were treated in parallel with either 25-50 nM SAPP $\alpha, 50 \mathrm{nM}$ APP-E1 domain or $20 \mathrm{nM}$ IGF1, as indicated. PTX (Enzo Life Sciences, $100 \mathrm{ng} / \mathrm{ml}$ ) or PI3K inhibitor LY294002 (Enzo Life Sciences, $10 \mu \mathrm{M}$ ) were applied $30 \mathrm{~min}$ before SAPP $\alpha$ was added to the medium. Following collection, cells were stained with $0.8 \mu \mathrm{g} / \mathrm{ml} \mathrm{PI}$, a DNA-intercalating and fluorescent agent, to visualize dead cells that emit red light at $617 \mathrm{~nm}$ when excited at $535 \mathrm{~nm}$. Cells were counted manually under a fluorescence microscope in three random visual fields ( $>150$ cells) and counter-stained with Hoechst to calculate the percentage of dead cells versus the total number of visualized cells. Alternatively, cells were stained with $\mathrm{PI}$ and analyzed with a FACS cytometer (BD Biosciences, Heidelberg, Germany). Organotypic hippocampal slices were incubated with $0.8 \mu \mathrm{g} / \mathrm{ml} \mathrm{PI}$ for 20 min at $37^{\circ} \mathrm{C}$. When applying the ADAM10 ( $\alpha$-secretase) inhibitor Gl254023X ( $5 \mu \mathrm{M})$, slices were cultured in serum-/glucose-free medium for $48 \mathrm{~h}$ containing the inhibitor or its respective carrier (DMSO) as control. Round circles of identical size (Ø $500 \mu \mathrm{m})$ were positioned in equivalent locations within the CA1 region of each hippocampus image and all PI-stained cells were counted using ImageJ software (NIH, Bethesda, MD, USA). Cell viability assays were performed with a commercial kit (CellTiter-Glo Luminescence Assay; Promega, Mannheim, Germany) according to the manufacturer's instructions. The assay quantitates ATP levels, an indicator of metabolically active cells, photometrically with a fluorescence plate reader. Additionally, we applied the live-dead cell staining kit II from PromoKine (Heidelberg, Germany) according to the manual. Cells were simultaneously stained with green fluorescent calcein-AM (4 mM; ex/em: 495/515 nm) to detect intracellular esterase activity (viable cells) and red fluorescent ethidium homodimer-3 ( $2 \mathrm{mM}$; ex/em: $530 / 635 \mathrm{~nm}$ ) to indicate loss of plasma membrane integrity (dead cells).

Akt kinase activity assays. Cell cultures were pre-treated with $10-50 \mathrm{nM}$ yeast-derived SAPP $\alpha / \mathrm{E} 1$ or $20 \mathrm{nM}$ human IGF1 for $24 \mathrm{~h}$ before removal of glucose and/or serum. During starvation for $24-48 \mathrm{~h}$, the same treatments were administered. IGF1 was added every $24 \mathrm{~h}$ owing to its short half-life. In the experiment using PTX, $100 \mathrm{ng} / \mathrm{ml}$ of the toxin was applied 30 min before SAPP $\alpha$ was added to the medium. Akt kinase activity was measured in vitro with a commercial kit (Akt kinase assay kit; Cell Signaling, Frankfurt/Main, Germany) according to the manufacturer's protocol. Briefly, endogenous levels of pAkt were immunoprecipitated from whole-cell extracts with immobilized pAkt (Ser473) mAb (bead conjugate) overnight. After extensive washing, the kinase assay was performed using $10 \mathrm{mM}$ ATP and GSK3 fusion protein $(27 \mathrm{kDa})$ as a substrate. Subsequent inactivation of GSK3 was measured by western blot detecting $\mathrm{pGSK} 3 \alpha / \beta$ (Ser 21/9, $27 \mathrm{kDa})$.

Immunoblotting. For western blotting, cells were washed with PBS, harvested and lysed with SDS lysis buffer (2\% SDS, $68.5 \mathrm{mM}$ Tris- $\mathrm{HCl}, 10 \%$ glycerin, $1 \mathrm{mM}$ protease/phosphatase inhibitor cocktail) or lysis buffer from the Akt kinase assay kit supplemented with $1 \mathrm{mM}$ PMSF followed by sonication. The protein amount was quantified using the Pierce BCA Protein Assay Kit (Thermo Fisher, Schwerte, Germany). Equal amounts were used for the Akt kinase assays or directly loaded onto $10-12 \%$ bis-acrylamide/SDS gels for conventional western blots and electrotransferred to nitrocellulose membranes (Whatman Protran BA 83, $0.2 \mu \mathrm{m}$; GE Healthcare, Little Chalfont, UK). Unspecific binding was blocked for $1 \mathrm{~h}$ in $5 \%$ non-fat powdered milk in $0.05 \%$ Tween-20 (v/v in TBS) followed by overnight incubation at $4{ }^{\circ} \mathrm{C}$ with primary antibodies specific for pGSK3 $\alpha / \beta$ (rabbit, Ser 21/9; Cell Signaling), pGSK3 $\beta$ (rabbit, D3A4; Cell Signaling), GSK3 $\beta$ (mouse, 3D10; Cell Signaling), APP (mouse, 22C11; Millipore, Darmstadt, Germany), Bim (rabbit; Cell Signaling) or APLP1/APLP2 (rabbit; Millipore). Equal loading was monitored by probing membranes with glyceraldehyde 3-phosphate dehydrogenase (GAPDH) (Millipore). The corresponding secondary antibodies coupled with infrared dyes in red (680 RD) or green $(800 \mathrm{CW})$ against rabbit or mouse (IRDye goat anti-rabbit or anti-mouse from LI-COR Biosciences, Bad Homburg, Germany) were diluted in $5 \%$ bovine serum albumin, followed by detection with the LI-COR Odyssey Infrared Imager (LI-COR Biosciences).

On-cell-Western assays were performed to evaluate cell surface expression of APP. The experiment was performed by adding primary antibody (22C11, 1:180) directly into the medium of live, unpermeabilized cells for $4 \mathrm{~h}$. After three washing steps with PBS, secondary antibody (IRDye goat anti-mouse from LI-COR; 1:1000) was incubated for $1 \mathrm{~h}$. Following washing steps, fluorescence signals were measured using the LI-COR Odyssey Infrared Imager and Image Studio 3.1 software (LI-COR Odyssey, Bad Homburg, Germany). Values are arbitrary fluorescence units calculated from trim signals (means of $n=3$ experiments \pm S.E.M.) normalized to background staining controls.

Statistical analyses and microscopy. Results are expressed as mean \pm S.E.M. All experiments were repeated at least three times yielding similar results. Statistical analyses were performed using SPSS (IBM, Armonk, NY, USA) with one-way ANOVA followed by Tukey's HSD post hoc comparisons. P-values $<0.05$ were considered as statistically significant. Western blot quantifications were performed with LI-COR Odyssey Image Studio 3.1 software to guarantee analysis of fluorescence signals in a linear range or ImageJ software for ECL-developed blots. Values were normalized to serum/glucose-treated controls (dashed line in figures). Band intensities in blots with whole-cell lysates were normalized to their corresponding loading control (GAPDH) and plotted as pGSK3 $\beta / G A P D H$ ratios. All graphs show means of $n=3$ blot quantifications \pm S.E.M. For microscopy, we used the Nikon Eclipse TE2000-S fluorescence microscope with Plan Fluor $\times 4, \times 10$ or $\times 20$ dry objectives, a 100 W mercury lamp and FITC (green; ex: $465-495 \mathrm{~nm}$; dichroic mirror: $505 \mathrm{~nm}$; em: $515-555 \mathrm{~nm}$ ) or Texas Red (red; ex: $540-580 \mathrm{~nm}$; dichroic mirror: $595 \mathrm{~nm}$; em: 600-660 nm) excitation filters. Images were acquired with a DS-5Mc cooled color digital camera (Nikon, Düsseldorf, Germany) and NIS Elements AR (version 3.22) software from Nikon. Image adjustments such as changes of contrast and brightness were applied equally across the entire image.

\section{Conflict of Interest}

The authors declare no conflict of interest.

Acknowledgements. This study was supported by the Deutsche Forschungsgemeinschaft (DFG; Grants KO 1898/6-1 and 10/1 to DK, 
BE 1475/8-1 to CB, KI 819/5-1 and 819/6-1 to SK, MU 1457/8-1 and 1457/9-1 to UCM, and by the BMBF funded NEURON-ERANET program to UCM (01EW1305A) and CJB (01EW1305B)). We thank Gabriele Köpf for excellent technical assistance and Andreas Zymny for providing the SH-SY5Y APP/ APLP1/APLP2 KD cells.

1. Zheng $\mathrm{H}, \mathrm{Koo} E \mathrm{EH}$. Biology and pathophysiology of the amyloid precursor protein. Mol Neurodegener 2011; 6: 27.

2. Aydin D, Weyer SW, Muller UC. Functions of the APP gene family in the nervous system insights from mouse models. Exp Brain Res 2012; 217: 423-434.

3. Muller UC, Zheng H. Physiological functions of APP family proteins. Cold Spring Harbor Perspect Med 2012; 2: a006288.

4. Selkoe DJ. Alzheimer's disease. Cold Spring Harbor Perspect Biol 2011; 3: 7.

5. Endres K, Fahrenholz F. Regulation of alpha-secretase ADAM10 expression and activity. Exp Brain Res 2012; 217: 343-352.

6. Muller UC, Pietrzik CU, Deller T. The physiological functions of the beta-amyloid precursor protein APP. Exp Brain Res 2012; 217: 325-329

7. Fahrenholz F. Alpha-secretase as a therapeutic target. Curr Alzheimer Res 2007; 4 412-417.

8. Baumkotter F, Wagner K, Eggert S, Wild K, Kins S. Structural aspects and physiological consequences of APP/APLP trans-dimerization. Exp Brain Res 2012; 217 389-395.

9. Herms J, Anliker B, Heber S, Ring S, Fuhrmann M, Kretzschmar H et al. Cortical dysplasia resembling human type 2 lissencephaly in mice lacking all three APP family members. EMBO J 2004; 23: 4106-4115.

10. Soba $\mathrm{P}$, Eggert $\mathrm{S}$, Wagner $\mathrm{K}$, Zentgraf $\mathrm{H}$, Siehl K, Kreger $\mathrm{S}$ et al. Homo- and heterodimerization of APP family members promotes intercellular adhesion. EMBO J2005; 24: 3624-3634

11. Ramirez MJ, Heslop KE, Francis PT, Rattray M. Expression of amyloid precursor protein, tau and presenilin RNAs in rat hippocampus following deafferentation lesions. Brain Res 2001; 907: 222-232

12. Murakami N, Yamaki T, Iwamoto Y, Sakakibara T, Kobori N, Fushiki S et al. Experimental brain injury induces expression of amyloid precursor protein, which may be related to neuronal loss in the hippocampus. J Neurotrauma 1998; 15: 993-1003.

13. Van den Heuvel C, Blumbergs PC, Finnie JW, Manavis J, Jones NR, Reilly PL et al. Upregulation of amyloid precursor protein messenger RNA in response to traumatic brain injury: an ovine head impact model. Exp Neurol 1999; 159: 441-450.

14. Leyssen M, Ayaz D, Hebert SS, Reeve S, De Strooper B, Hassan BA. Amyloid precursor protein promotes post-developmental neurite arborization in the Drosophila brain. EMBO 2005; 24: 2944-2955.

15. Wentzell JS, Bolkan BJ, Carmine-Simmen K, Swanson TL, Musashe DT, Kretzschmar D. Amyloid precursor proteins are protective in Drosophila models of progressive neurodegeneration. Neurobiol Dis 2012; 46: 78-87.

16. Corrigan F, Pham CL, Vink R, Blumbergs PC, Masters $C L$, van den Heuvel $C$ et al. The neuroprotective domains of the amyloid precursor protein, in traumatic brain injury, are located in the two growth factor domains. Brain Res 2011; 1378: 137-143.

17. Masliah E, Westland CE, Rockenstein EM, Abraham CR, Mallory M, Veinberg I et al. Amyloid precursor proteins protect neurons of transgenic mice against acute and chronic excitotoxic injuries in vivo. Neuroscience 1997; 78: 135-146.

18. Mucke L, Abraham CR, Masliah E. Neurotrophic and neuroprotective effects of hAPP in transgenic mice. Ann NY Acad Sci 1996; 777: 82-88.

19. Smith-Swintosky VL, Pettigrew LC, Craddock SD, Culwell AR, Rydel RE, Mattson MP. Secreted forms of beta-amyloid precursor protein protect against ischemic brain injury. J Neurochem 1994; 63: 781-784.

20. Steinbach JP, Muller U, Leist M, Li ZW, Nicotera P, Aguzzi A. Hypersensitivity to seizures in beta-amyloid precursor protein deficient mice. Cell Death Differ 1998; 5 858-866

21. Furukawa K, Mattson MP. Secreted amyloid precursor protein alpha selectively suppresses $\mathrm{N}$-methyl-D-aspartate currents in hippocampal neurons: involvement of cyclic GMP. Neuroscience 1998; 83: 429-438.

22. Goodman Y, Mattson MP. Secreted forms of beta-amyloid precursor protein protect hippocampal neurons against amyloid beta-peptide-induced oxidative injury. Exp Neurol 1994; 128: 1-12.

23. Gralle M, Botelho MG, Wouters FS. Neuroprotective secreted amyloid precursor protein acts by disrupting amyloid precursor protein dimers. J Biol Chem 2009; 284 15016-15025.

24. Han P, Dou F, Li F, Zhang X, Zhang YW, Zheng H et al. Suppression of cyclin-dependent kinase 5 activation by amyloid precursor protein: a novel excitoprotective mechanism involving modulation of tau phosphorylation. J Neurosci 2005; 25: 11542-11552.

25. Kögel D, Schomburg R, Copanaki E, Prehn JH. Regulation of gene expression by the amyloid precursor protein: inhibition of the JNK/c-Jun pathway. Cell Death Differ 2005; 12 $1-9$

26. Kögel D, Schomburg R, Schürmann T, Reimertz C, König HG, Poppe M et al. The amyloid precursor protein protects $\mathrm{PC} 12$ cells against endoplasmic reticulum stress-induced apoptosis. J Neurochem 2003; 87: 248-256.
27. Mattson MP, Cheng B, Culwell AR, Esch FS, Lieberburg I, Rydel RE. Evidence for excitoprotective and intraneuronal calcium-regulating roles for secreted forms of the beta-amyloid precursor protein. Neuron 1993; 10: 243-254.

28. Schubert $\mathrm{D}, \mathrm{Behl} \mathrm{C}$. The expression of amyloid beta protein precursor protects nerve cells from beta-amyloid and glutamate toxicity and alters their interaction with the extracellular matrix. Brain Res 1993; 629: 275-282.

29. Stein TD, Anders NJ, DeCarli C, Chan SL, Mattson MP, Johnson JA. Neutralization of transthyretin reverses the neuroprotective effects of secreted amyloid precursor protein (APP) in APPSW mice resulting in tau phosphorylation and loss of hippocampal neurons: support for the amyloid hypothesis. J Neurosci 2004; 24: 7707-7717.

30. Xu X, Yang D, Wyss-Coray T, Yan J, Gan L, Sun Y et al. Wild-type but not Alzheimer-mutant amyloid precursor protein confers resistance against p53-mediated apoptosis. Proc Natl Acad Sci USA 1999; 96: 7547-7552.

31. Roch JM, Masliah E, Roch-Levecq AC, Sundsmo MP, Otero DA, Veinbergs I et al. Increase of synaptic density and memory retention by a peptide representing the trophic domain of the amyloid beta/A4 protein precursor. Proc Natl Acad Sci USA 1994; 91: 7450-7454

32. Kögel D, Deller T, Behl C. Roles of amyloid precursor protein family members in neuroprotection, stress signaling and aging. Exp Brain Res 2012; 217: 471-479.

33. Mattson MP, Mark RJ, Furukawa K, Bruce AJ. Disruption of brain cell ion homeostasis in Alzheimer's disease by oxy radicals, and signaling pathways that protect therefrom. Chem Res Toxicol 1997; 10: 507-517.

34. Furukawa K, Barger SW, Blalock EM, Mattson MP. Activation of $\mathrm{K}+$ channels and suppression of neuronal activity by secreted beta-amyloid-precursor protein. Nature 1996; 379: 74-78.

35. LaFerla FM. Calcium dyshomeostasis and intracellular signalling in Alzheimer's disease. Nat Rev Neurosci 2002; 3: 862-872.

36. Putcha GV, Le S, Frank S, Besirli CG, Clark K, Chu B et al. JNK-mediated BIM phosphorylation potentiates BAX-dependent apoptosis. Neuron 2003; 38 : 899-914.

37. Copanaki E, Chang S, Vlachos A, Tschape JA, Muller UC, Kogel D et al. sAPPalpha antagonizes dendritic degeneration and neuron death triggered by proteasomal stress. Mol Cell Neurosci 2010; 44: 386-393.

38. Eckert GP, Chang S, Eckmann J, Copanaki E, Hagl S, Hener U et al. Liposome-incorporated DHA increases neuronal survival by enhancing non-amyloidogenic APP processing. Biochim Biophys Acta 2011; 1808: 236-243.

39. Cheng G, Yu Z, Zhou D, Mattson MP. Phosphatidylinositol-3-kinase-Akt kinase and p42/p44 mitogen-activated protein kinases mediate neurotrophic and excitoprotective actions of a secreted form of amyloid precursor protein. Exp Neurol 2002; 175 . 407-414

40. Weyer SW, Klevanski M, Delekate A, Voikar V, Aydin D, Hick M et al. APP and APLP2 are essential at PNS and CNS synapses for transmission, spatial learning and LTP. EMBO J 2011; 30: 2266-2280.

41. Ring S, Weyer SW, Kilian SB, Waldron E, Pietrzik CU, Filippov MA et al. The secreted beta-amyloid precursor protein ectodomain APPs alpha is sufficient to rescue the anatomical, behavioral, and electrophysiological abnormalities of APP-deficient mice. J Neurosci 2007; 27: 7817-7826.

42. Müller T, Meyer HE, Egensperger R, Marcus K. The amyloid precursor protein intracellular domain (AICD) as modulator of gene expression, apoptosis, and cytoskeletal dynamicsrelevance for Alzheimer's disease. Prog Neurobiol 2008; 85: 393-406.

43. Back S, Haas P, Tschape JA, Gruebl T, Kirsch J, Muller U et al. Beta-amyloid precursor protein can be transported independent of any sorting signal to the axonal and dendritic compartment. J Neurosci Res 2007; 85: 2580-2590.

44. Merdes G, Soba P, Loewer A, Bilic MV, Beyreuther K, Paro R. Interference of human and Drosophila APP and APP-like proteins with PNS development in Drosophila. EMBO J 2004; 23: 4082-4095

45. Deyts C, Vetrivel KS, Das S, Shepherd YM, Dupre DJ, Thinakaran G et al. Novel GalphaS-protein signaling associated with membrane-tethered amyloid precursor protein intracellular domain. J Neurosci 2012; 32: 1714-1729.

46. Nikolaev A, McLaughlin T, O'Leary DD, Tessier-Lavigne M. APP binds DR6 to trigger axon pruning and neuron death via distinct caspases. Nature 2009; 457: 981-989.

47. Kögel D, Concannon CG, Muller T, König H, Bonner C, Poeschel S et al. The APP intracellular domain (AICD) potentiates ER stress-induced apoptosis. Neurobiol Aging 2012; 33: 2200-2209

48. Jimenez S, Torres M, Vizuete M, Sanchez-Varo R, Sanchez-Mejias E, Trujillo-Estrada L et al. Age-dependent accumulation of soluble amyloid \{beta\} (A\{beta\}) oligomers reverses the neuroprotective effect of soluble amyloid precursor protein-\{alpha\} (sAPP\{alpha\}) by modulating phosphatidylinositol 3-kinase (PI3K)/Akt-GSK-3\{beta\} pathway in Alzheimer mouse model. J Biol Chem 2011; 286: 18414-18425

49. Furukawa K, Sopher BL, Rydel RE, Begley JG, Pham DG, Martin GM et al. Increased activity-regulating and neuroprotective efficacy of alpha-secretase-derived secreted amyloid precursor protein conferred by a C-terminal heparin-binding domain. J Neurochem 1996; 67: 1882-1896.

50. Crews L, Masliah E. Molecular mechanisms of neurodegeneration in Alzheimer's disease. Hum Mol Genet 2010; 19: R12-R20.

51. Endres K, Fahrenholz F. The role of the anti-amyloidogenic secretase ADAM10 in shedding the APP-like proteins. Curr Alzheimer Res 2011. 
52. Hogl S, Kuhn PH, Colombo A, Lichtenthaler SF. Determination of the proteolytic cleavage sites of the amyloid precursor-like protein 2 by the proteases ADAM10, BACE1 and gamma-secretase. PLoS One 2011; 6: e21337.

53. Adlerz L, Holback S, Multhaup G, Iverfeldt K. IGF-1-induced processing of the amyloid precursor protein family is mediated by different signaling pathways. J Biol Chem 2007; 282: 10203-10209.

54. Venezia V, Nizzari M, Repetto E, Violani E, Corsaro A, Thellung S et al. Amyloid precursor protein modulates ERK-1 and -2 signaling. Ann NY Acad Sci 2006; 1090: 455-465.

55. Nishimoto I, Okamoto T, Matsuura Y, Takahashi S, Murayama Y, Ogata E. Alzheimer amyloid protein precursor complexes with brain GTP-binding protein $\mathrm{G}(0)$. Nature 1993; 362: 75-79.

56. Murga C, Fukuhara S, Gutkind JS. A novel role for phosphatidylinositol 3-kinase beta in signaling from G protein-coupled receptors to Akt. J Biol Chem 2000; 275: 12069-12073.

57. Murga C, Laguinge L, Wetzker R, Cuadrado A, Gutkind JS. Activation of Akt/protein kinase $B$ by $G$ protein-coupled receptors. A role for alpha and beta gamma subunits of heterotrimeric $\mathrm{G}$ proteins acting through phosphatidylinositol-3-OH kinasegamma. J Biol Chem 1998; 273: 19080-19085.

58. Li ZW, Stark G, Gotz J, Rulicke T, Gschwind M, Huber G et al. Generation of mice with a 200-kb amyloid precursor protein gene deletion by Cre recombinase-mediated site-specific recombination in embryonic stem cells. Proc Natl Acad Sci USA 1996; 93: 6158-6162.
59. Stoppini L, Buchs PA, Muller D. A simple method for organotypic cultures of nervous tissue. J Neurosci Methods 1991; 37: 173-182.

60. Anliker B, Abel T, Kneissl S, Hlavaty J, Caputi A, Brynza J et al. Specific gene transfer to neurons, endothelial cells and hematopoietic progenitors with lentiviral vectors. Nat Methods 2010; 7: 929-935.

(c) (i) $(-)$ Cell Death and Disease is an open-access journal published by Nature Publishing Group. This work is licensed under a Creative Commons Attribution-NonCommercialNoDerivs 3.0 Unported License. The images or other third party material in this article are included in the article's Creative Commons license, unless indicated otherwise in the credit line; if the material is not included under the Creative Commons license, users will need to obtain permission from the license holder to reproduce the material. To view a copy of this license, visit http://creativecommons.org/licenses/ by-nc-nd/3.0/

Supplementary Information accompanies this paper on Cell Death and Disease website (http://www.nature.com/cddis) 